\title{
Increasing HIV Testing and Viral Suppression via Stigma Reduction in a Social Networking Mobile Health Intervention Among Black and Latinx Young Men and Transgender Women Who Have Sex With Men (HealthMpowerment): Protocol for a Randomized Controlled Trial
}

Kathryn Elizabeth Muessig ${ }^{1}$, BA, PhD; Jesse M Golinkoff ${ }^{2}$, MPH; Lisa B Hightow-Weidman ${ }^{3}$, MPH, MD; Aimee E Rochelle $^{4}$, MPH; Marta I Mulawa ${ }^{5}$, MHS, PhD; Sabina Hirshfield ${ }^{6}$, PhD; A Lina Rosengren ${ }^{3}$, MPH, MS, MD; Subhash $\mathrm{Aryal}^{2}, \mathrm{PhD} ;$ Nickie Buckner ${ }^{7}, \mathrm{BS}, \mathrm{MCS} ; \mathrm{M}$ Skye Wilson ${ }^{4}$, MSED; Dovie L Watson ${ }^{8}$, MSCE, MD; Steven Houang ${ }^{1}$, BA; José Arturo Bauermeister ${ }^{2}$, MPH, PhD

\footnotetext{
${ }^{1}$ Department of Health Behavior, Gillings School of Global Public Health, University of North Carolina at Chapel Hill, Chapel Hill, NC, United States

${ }^{2}$ Department of Family and Community Health, School of Nursing, University of Pennsylvania, Philadelphia, PA, United States

${ }^{3}$ Division of Infectious Diseases, School of Medicine, University of North Carolina at Chapel Hill, Chapel Hill, NC, United States

${ }^{4}$ Behavior and Technology Lab, Institute for Global Health and Infectious Diseases, University of North Carolina at Chapel Hill, Chapel Hill, NC, United States

${ }^{5}$ School of Nursing, Duke University, Durham, NC, United States

${ }^{6}$ Department of Medicine, SUNY Downstate Health Sciences University, Brooklyn, NY, United States

${ }^{7}$ One Cow Standing, LLC, Durham, NC, United States

${ }^{8}$ Department of Medicine, Perelman School of Medicine, University of Pennsylvania, Philadelphia, PA, United States
}

\section{Corresponding Author:}

Kathryn Elizabeth Muessig, BA, PhD

Department of Health Behavior

Gillings School of Global Public Health

University of North Carolina at Chapel Hill

135 Dauer Drive

Chapel Hill, NC, 27599

United States

Phone: 19199625059

Email: kmuessig@med.unc.edu

\section{Abstract}

Background: Stigma and discrimination related to sexuality, race, ethnicity, and HIV status negatively impact HIV testing, engagement in care, and consistent viral suppression (VS) among young Black and Latinx men who have sex with men and transgender women who have sex with men (YBLMT). Few interventions address the effects of intersectional stigma among youth living with HIV and those at risk for HIV within the same virtual space.

Objective: Building on the success of the HealthMpowerment (HMP) mobile health (mHealth) intervention (HMP 1.0) and with the input of a youth advisory board, HMP 2.0 is an app-based intervention that promotes user-generated content and social support to reduce intersectional stigma and improve HIV-related outcomes among YBLMT. The primary objective of this study is to test whether participants randomized to HMP 2.0 report improvement in HIV prevention and care continuum outcomes compared with an information-only control arm. We will also explore whether participant engagement, as measured by paradata (data collected as users interact with an mHealth intervention, eg, time spent using the intervention), mediates stigma- and HIV care-related outcomes. Finally, we will assess whether changes in intersectional stigma and improvements in HIV care continuum outcomes vary across different types of social networks formed within the intervention study arms.

Methods: We will enroll 1050 YBLMT aged 15 to 29 years affected by HIV across the United States. Using an HIV-status stratified, randomized trial design, participants will be randomly assigned to 1 of the 3 app-based conditions (information-only 
app-based control arm, a researcher-created network arm of HMP 2.0, or a peer-referred network arm of HMP 2.0). Behavioral assessments will occur at baseline, 3, 6, 9, and 12 months. For participants living with HIV, self-collected biomarkers (viral load) are scheduled for baseline, 6, and 12 months. For HIV-negative participants, up to 3 HIV self-testing kits will be available during the study period.

Results: Research activities began in September 2018 and are ongoing. The University of Pennsylvania is the central institutional review board for this study (protocol \#829805) with institutional reliance agreements with the University of North Carolina at Chapel Hill, Duke University, and SUNY Downstate Health Sciences University. Study recruitment began on July 20, 2020. A total of 205 participants have been enrolled as of November 20, 2020.

Conclusions: Among a large sample of US-based YBLMT, this study will assess whether HMP 2.0, an app-based intervention designed to ameliorate stigma and its negative sequelae, can increase routine HIV testing among HIV-negative participants and consistent VS among participants living with HIV. If efficacious and brought to scale, this intervention has the potential to significantly impact the disproportionate burden of HIV among YBLMT in the United States.

Trial Registration: ClinicalTrials.gov NCT03678181; https://clinicaltrials.gov/ct2/show/study/NCT03678181.

International Registered Report Identifier (IRRID): DERR1-10.2196/24043

(JMIR Res Protoc 2020;9(12):e24043) doi: $\underline{10.2196 / 24043}$

\section{KEYWORDS}

HIV; mHealth; smartphone; men who have sex with men; racism; transgender; Hispanic Americans; mobile phone; African American

\section{Introduction}

\section{Background}

Young Black and Latinx men who have sex with men and transgender women who have sex with men (YBLMT) have the highest rates of new HIV diagnoses compared with non-Hispanic White peers of the same age [1], even when engaging in fewer individual-level risk behaviors [2-4]. YBLMT face multiple stigmas, racism, and discrimination related to their sexual orientation, gender, race, ethnicity, and HIV status that constrain options for building healthy relationships and supportive networks; this contributes to social isolation, inhibiting protective behaviors (eg, consistent condom use, uptake of pre-exposure prophylaxis [PrEP], and adherence to antiretroviral therapy [ART]) [5-9]. These stigmas and discriminatory practices are institutionalized and perpetuated in the systems and environments of daily life, posing barriers to engagement in care such as regular HIV testing, PrEP and ART persistence, and attending HIV care appointments [10-17]. Stigma- and discrimination-related stressors have additive or multiplicative negative physical, social, and mental health effects at the individual, interpersonal, community, and structural levels [18-23].

Although a growing number of interventions aim to address individual- or community-level HIV stigma [24,25] or consider YBLMT intersecting identities [26-30], few focus on addressing intersectional stigma as a primary mechanism for improving HIV prevention and care [31]. Furthermore, most stigma-focused interventions are delivered in person, are not tailored for the unique developmental stages of youth and young adulthood, and focus on either HIV-positive or HIV-negative populations [27,28,32-36]. The social and logistical requirements of attending in-person interventions may not fit the realities of YBLMT, particularly if they are geographically isolated [37] or have perceived discrimination or experienced microaggressions within the health care system [15,38,39].
Segmenting participants by HIV status could further polarize individuals in the community, reinforcing rather than reducing HIV-related stigma [40,41]. The biomedical advances of PrEP and Treatment as Prevention and the undetectable equals untransmittable $(\mathrm{U}=\mathrm{U})$ movement necessitate more inclusive, accessible intervention approaches [42].

As a strengths-based approach, social networks hold the potential power to resist stigma and improve HIV prevention and care continuum for YBLMT [43-47]. Networks also offer a unique way to understand how stigma norms and beliefs are reinforced or deconstructed. Understanding these processes within networks is important because of the critical roles of connectivity and collective identity in resilience [48-50]. A smartphone-delivered intervention that draws on the strengths of social networks could alleviate barriers to access in-person interventions, facilitate more open dialogue addressing intersectional stigma, and encourage HIV testing and care through supportive interactions with peers across the country [51-56]. Widespread access to smartphones among YBLMT in the United States makes this modality an ideal approach for increasing intervention access and reach [37,57].

A number of mobile health (mHealth) interventions are currently being developed or adapted for YBLMT [54,58-63]; however, few explicitly address the influence of intersectional stigma on HIV care outcomes or take an inclusive approach across HIV status. To address these gaps and barriers, we created an intervention strategy focused on fostering community, providing resources, and amplifying the existing strengths and assets of YBLMT $[13,49,64]$. The original HealthMpowerment (HMP) intervention and mHealth platform (HMP 1.0) was designed and delivered as a 3-month intervention to increase safer sex behaviors; foster community among YBLMT; and remove logistical, financial, and psychosocial barriers to intervention engagement [58]. The HMP 1.0 intervention yielded significant reductions in condomless anal intercourse (CAI) in a randomized controlled trial (RCT) conducted in the southeastern United 
States [58]. The social support features of HMP 1.0 were the most frequently used intervention components, and engagement with these features was associated with improved HIV care outcomes [31]. We also found associations between engaging with stigma-related content and both psychosocial and physical health outcomes [31,65-67].

\section{Objectives}

Building on the success and lessons learned with HMP 1.0, and with the input of a youth advisory board (YAB), we rebuilt the intervention platform to reflect participant feedback and advances in technology and design. The HMP 2.0 platform maintains strong social and informational support features and enhanced intervention components. Content focuses on fostering stigma amelioration with the goals of strengthening the continued engagement of YBLMT in HIV testing for those who are HIV negative and sustained viral suppression (VS) for youth living with HIV. Our study will also address a gap in knowledge regarding how participant engagement with mHealth interventions is linked to HIV prevention and care outcomes [68-70]. We will use paradata metrics (data automatically collected as users interact with mHealth interventions such as time stamps in system logs to quantify time spent using the intervention) to gauge how intersectional stigma- and HIV-related outcomes differ based on participants' frequency of use (exposure), amount of time spent (engagement), and types of intervention components used (usage) on the app [71].

This intervention trial is built on the scientific premise that network interventions can support behavior change $[21,22,43,45,46,72,73]$. Given that YBLMT widely use web-based networking sites and apps to socialize with peers [51,53,74-76], HMP 2.0 promotes social support by creating a connected virtual community [56]. We hypothesize that compared with YBLMT assigned to an information-only app condition, YBLMT assigned to an intervention arm of HMP 2.0 will report greater changes in stigma-related measures (eg, anticipated stigma, internalized stigma) and be more successful at buffering the negative sequelae of intersectional stigma and circumventing barriers to successful engagement in the HIV prevention and care continuum [46,77]. As the structural (eg, size, density) and interactional (eg, relational roles between ties; frequency and reciprocity between actors) components of a network also affect behaviors [78-85], we will compare efficacy and engagement levels between 2 types of recruitment networks: a researcher-created network and a peer-referred network. We hypothesize that participants assigned to the peer-referral network condition will have greater success in eliciting peer social support, engaging with the intervention, and achieving the desired stigma- and HIV-related outcomes than participants in the researcher-created network condition.

\section{Methods}

\section{Timeline}

This project began in September 2018. The initial period of study start-up activities (eg, obtaining institutional review board [IRB] approvals, hiring and training staff, rebuilding the intervention platform structure, developing the study protocol and study-specific procedures, recruiting YAB members) lasted until September 2019. October 2019 to June 2020 consisted of working with the research team, technology partner, and YAB members to update and expand intervention content; finalize and program all study tools; create HIV and viral load self-testing multimedia support materials and shipping procedures; establish robust recruitment, retention, and engagement plans; and optimize the functionality and usability of the intervention platform and administrators' data management dashboard. Recruitment began in July 2020 and is anticipated to complete between June and September 2022. Final participant follow-ups will end by September 2023 followed by data analysis, and the study results will be disseminated in 2024.

\section{Study Design}

The study design is a 3-arm, 12-month prospective RCT enrolling a total of 1050 men who have sex with men (MSM) and transgender women (TW) across the United States. The research team will recruit and enroll 750 participants; the remaining 300 will be referred by enrolled participants. Of the 750 researcher-recruited participants, 300 will be HIV negative and 450 will be HIV positive. Participants' self-reported HIV status at baseline will be used for allocation in our HIV-status stratified randomization procedure (Figure 1). Researcher-recruited participants who self-reported as HIV negative or serostatus unknown will be randomized $(1: 1 ; n=150$ per arm) into either the information-only control arm (arm 1) or the researcher-created network ( $\operatorname{arm} 2)$. Researcher-recruited participants who self-report as HIV positive will be randomized across all 3 study arms $(1: 1: 1 ; n=150$ per arm). Researcher-recruited HIV-positive participants randomized to the peer-referral network arm (arm 3; $n=150)$ can then invite peers to participate in the intervention. Up to 2 eligible referred peers may enroll per arm 3 researcher-recruited participant. These peers will be directly assigned to study arm 3 (not randomized); referred peers who enroll may not subsequently refer other peers. We estimate that approximately half of the participant-referred enrolled peers will be HIV negative or sero-unknown (Figure 1). 
Figure 1. HealthMpowerment intervention enrollment and randomization procedural flow diagram. SOP: standard operating procedure.

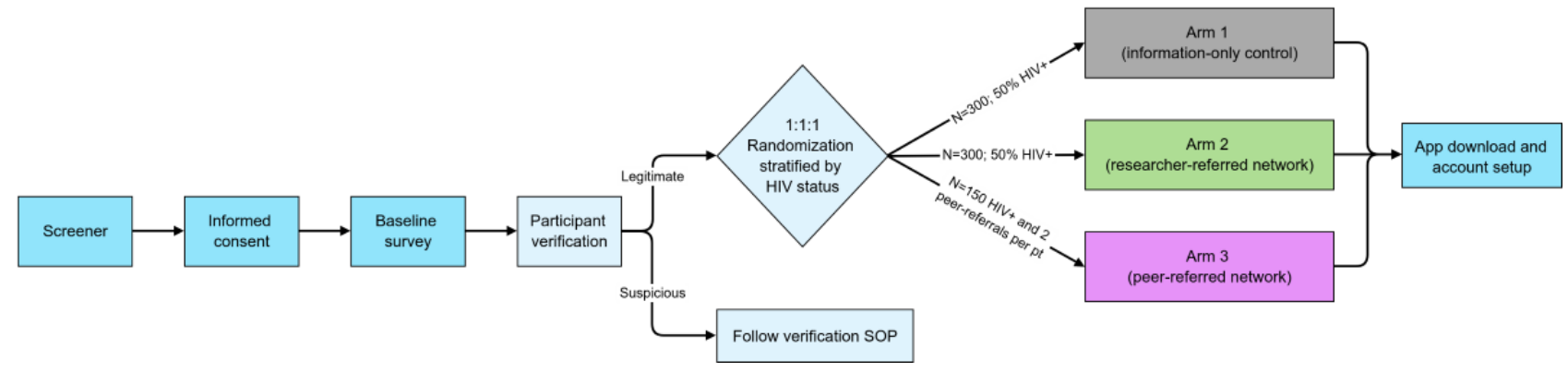

Study assessments will be administered at baseline, 6, and 12 months. An abbreviated version of the study assessment is administered at months 3 and 9. Consistent with best practices, we will use validated measures developed as part of the US National Institutes of Health Adolescent Medicine Trials Network for HIV/AIDS Interventions studies [86].

\section{HMP 2.0 Intervention}

\section{Theoretical Foundations}

The theoretical foundation of HMP 2.0 builds on the intervention's original behavior change theory-the Integrated Behavior Model [87] - and increases the salience of stigma-related beliefs, norms, and attitudes through new intervention content and activities, as informed by the Conceptual Framework for HIV-Related Stigma, Engagement in Care, and Health Outcomes (the Stigma Framework) [88]. Structural stigma and intersectionality are overarching phenomena of the Stigma Framework. Stigma, racism, and discrimination are manifested in the social and institutional structures (eg, laws, policies, norms) that create and perpetuate disadvantage for marginalized groups [89]. Intersectionality theory proposes that the social categorizations of marginalized identities (eg, gender, sexuality, race) are not distinct but rather work together to produce and reproduce inequities [90-93]. These contexts are central to HMP 2.0's intervention approach on the premise that stigma and discrimination shape the health and health care experiences of YBLMT and should thus be a primary target of intervention.

The Stigma Framework reflects the foundational HIV stigma work [94-96] categorizing 4 types of stigma: discriminatory events and experiences (enacted stigma), perceptions of society's stigmatizing attitudes (community stigma), expectations of future discrimination (anticipated stigma), and acceptance of negative societal attitudes as part of one's own beliefs (internalized stigma) [88]. The HMP 2.0 intervention features tailored content and study measures across these 4 dimensions of stigma and also categorizes a fifth dimension of challenging stigma, that is, the acts of naming, confronting, resisting, or otherwise countering stigmatizing experiences, beliefs, narratives, practices, and perceptions [13,65]. In the HMP 1.0 trial, $75 \%$ of all participant-contributed stigma-related content could be categorized as challenging stigma, underscoring its importance within this virtual space [67] and its potential role in fostering resilience and resisting stigma and discrimination $[50,65]$. In applying the Stigma Framework, we categorize these 5 dimensions of stigma across content about race and ethnicity, gender, sexuality, and HIV.
Finally, the Stigma Framework proposes 4 types of mechanisms operating between stigma and engagement in care and HIV-related outcomes: interpersonal factors, psychological resources, mental health, and stress processes. Psychological resources include the "tools, skills, and personal identities that individuals use to cope with stressful life events" [88]. Stigma is negatively associated with these factors [97] and they may also act as buffers along the pathway to HIV-related outcomes [44]. Mental health refers to the relationship between stigma and depression and anxiety [98]. Finally, stress processes consider the biological pathways that are activated and may have a direct or mediated impact on HIV-related outcomes. A scientific premise of HMP 2.0 is that because of multiple stigmas and discrimination, stress processes are constantly activated among YBLMT. The intervention content and community-focused design aims to raise awareness of these stressors among participants, reinforce and model positive coping strategies, and ameliorate and discourage negative coping.

HMP 2.0 incorporates interpersonal-level components through its social support and social networking approach. Analyses will employ a network dynamics perspective and explore how stigma processes operate in interactions between individuals on the intervention. Psychological resources support a range of prohealth behaviors and constructs, including adherence self-efficacy, self-esteem, and coping skills. HMP 2.0 includes a substantial focus on mental health and wellness resources, activities, and discussion. A care navigator provides tailored referral support through the app.

\section{$Y A B$}

Youth involvement is vital when designing and executing a youth-focused HIV intervention [5,7,10]. Alongside the research team, we convened a YAB that includes members recruited nationally through social media (Instagram, Facebook, Twitter, and Craigslist), the Adolescent Medicine Trials Network for HIV/AIDS Interventions, and community contacts with groups that serve Black or Latinx queer communities. The YAB members are diverse in terms of age (21-29 years), race and ethnicity (3 Latinx members, 6 Black members, and 1 Black Native American member), HIV status (not reported for confidentiality), sexual orientation (not reported for confidentiality), and gender identity (8 cisgender men and 2 TW). States currently represented include Georgia, Louisiana, Michigan, New York, North Carolina, and Pennsylvania.

During intervention development, YAB members met biweekly with a designated research team member (YAB coordinator), 
either one-on-one or through group sessions, and provided iterative feedback as intervention functionality and content were updated, study protocol decisions were considered, and study materials and tools were developed. YAB members provided written and oral feedback; study staff took detailed notes during group discussions. Members reviewed forum topics and prepopulated comments and the organization and content of the Resources section for readability, comprehension, and relevance. They also identified gaps in content and suggested edits for language, tone, and imagery. Differences in opinions and perspectives emerged; however, none were divisive. Recognizing that these differences would also likely be reflected among study participants, the research team attempted to incorporate these multiple perspectives into intervention design and content. When relevant, the team gave greater weight to options that had a stronger evidence base or were more technologically feasible. Detailed descriptive processes regarding the YAB are planned for a YAB-focused paper, including YAB co-authorship.
During the active intervention (July 2020 to June 2023), YAB members will contribute on the forums in both intervention arms (2 and 3). Their HMP usernames will be preceded with "YAB" and feature a distinct avatar icon (Figure 2) and they will help monitor the forums for ideas for new content and flag any posts that do not follow the HMP 2.0 community guidelines of mutual respect. Interested YAB members will receive additional training to support writing new content for the intervention and analyzing the participant-contributed forum conversations. YAB members are considered integral members of the study team and receive a stipend commensurate with their time contributed each month. In addition to their monthly stipend, YAB members work with a YAB coordinator to create personalized professional development plans.

Development activities range from resume and interview preparation to connecting and networking with professionals in their fields of interest. The YAB coordinator also identifies shared interests among the group and facilitates opportunities for group professional development.

Figure 2. Screenshot of all icons for HealthMpowerment (HMP) 2.0 nonparticipant roles.

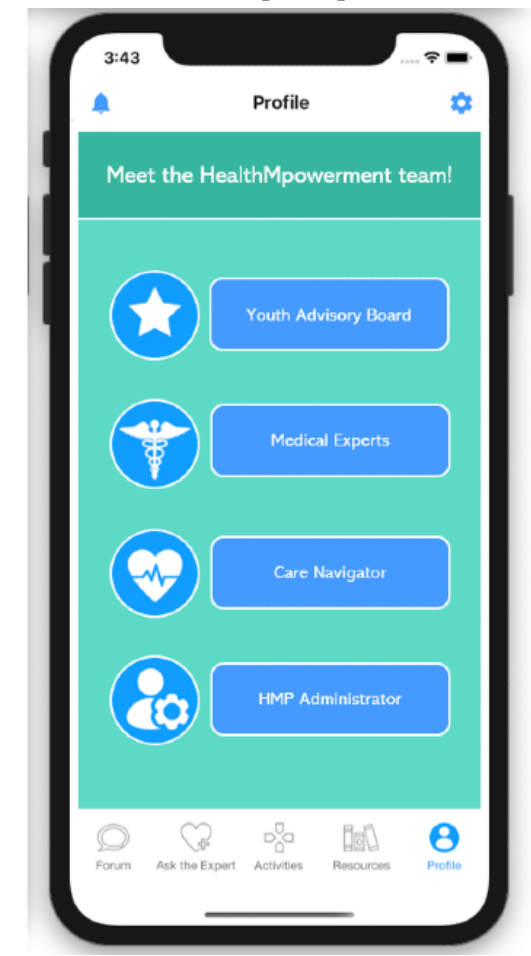

\section{Intervention Components}

\section{Intervention Features}

Table 1 presents brief descriptions of the core components of HMP 2.0 aligned with the theoretical underpinnings for addressing stigma and changing behavior. Modifications to the intervention were guided by the HMP 1.0 trial evaluation [65-67], the Stigma Framework developed by Turan et al [88], the YAB study, and advances in the science of HIV prevention, care, and health communication (eg, PrEP, U=U). 
Table 1. HealthMpowerment 2.0 core components, scientific rationale, and measurement metrics.

\begin{tabular}{|c|c|}
\hline Features & Description \\
\hline \multicolumn{2}{|c|}{ Base app components for all study arms 1, 2, and 3} \\
\hline Resource center & $\begin{array}{l}\text { Multimedia resources and information on } \\
\text { health and wellness, stigma, resilience, and }\end{array}$ \\
\hline & $\begin{array}{l}\text { life skills - tailored for YBLMT } \text { Y }^{\mathrm{a}} \text {, inclusive } \\
\text { learning styles and health literacy } \\
\text { Robust management system to create and } \\
\text { tailor new content and activities }\end{array}$ \\
\hline Test kit ordering & $\begin{array}{l}\text { - Ability to order and track HIV self-test kit } \\
\text { and viral load self-collection test } \\
\text { HIV test result image upload to app triggers } \\
\text { care navigator follow-up }\end{array}$ \\
\hline Care navigator & $\begin{array}{l}\text { Facilitates referral and linkage to HIV ser- } \\
\text { vices in the participant's local community } \\
\text { Follows up on unreported HIV test results } \\
\text { and all shared unclear and positive results } \\
\text { - Supports app engagement and retention } \\
\text { Troubleshoots and triages participant ques- } \\
\text { tions within the app to medical, study, and } \\
\text { technology teams }\end{array}$ \\
\hline
\end{tabular}

\section{Interactive app components for intervention arms 2 and 3}

Profile

Activities

Ask an expert

Gamification
- Personalized, anonymous username, avatar, brief bio, badges earned, and activities completed

- Activity templates include quizzes, self-assessments, goal setting, choose-your-ownadventure, sorting, and matching

- $\quad \mathrm{HIV}, \mathrm{STI}^{\mathrm{c}}$, sex questions answered by boardcertified physicians

- Care navigator directs participants to on- and off-app follow-up resources

Forums

- Start or add to existing discussions, upload images, videos, memes, etc

- $\quad$ Favorite posts and follow others

- Staff monitor and add to forum posts and include polls to encourage dialogue

- $\quad$ Sophisticated tracking of app use to trigger behavior-specific rewards

- Badges awarded for tracked events

\section{Peer network referral features for intervention arm 3 only}

Peer referral cen- • Unique referral code provided to share with ter peers

- Participant can track how many of their referred peers have successfully enrolled and then link to their in-app profiles
Scientific rationale (measurement metrics)

Content corresponds to and extends the $\mathrm{HMP}^{\mathrm{b}} 1.0$ intervention and aligns with the Integrated Behavior Model (number of articles read and total time spent)

Provides an opportunity to get tested by reducing barriers to in-person testing (number of test kits ordered and results uploaded to app or received by laboratory)

Increases intervention tailoring and linkage to care for nonclinic-based study. Provides equipoise and reduces risk of social harms for remote study with HIV at-risk minors. Supports use of self-testing and self-collection for youth (number of questions asked, content of questions, and participant satisfaction)

Personalization, gamification, and cues to action incentivize engagement (number of times visited and profile sections completed)

Interactive features will enhance learning, skill building and coping skills (number of activities done and total time)

Provide evidence-based answers to participants' health questions (number of questions asked, total time, and content of questions)

Forum topics correspond to Stigma Framework constructs. Peer support for resilience and behavior change (number of posts, comments, and likes; total time; content of posts)

Gamification features incentivize continued engagement (number of log-ins and badges earned)

YBLMT widely use networking sites and apps to socialize with peers. Structural and relational aspects of social networks affect decision making and behaviors (number of peers referred and enrolled, characteristics, eg, size, density, and diversity of intervention networks)

${ }^{a}$ YBLMT: young Black or Latino men who have sex with men and transgender women.

${ }^{b}$ HMP: HealthMpowerment.

${ }^{\mathrm{c}} \mathrm{STI}$ : sexually transmitted infection. 


\section{HMP 2.0 App Intervention Study Arms}

\section{Information-Only Control Group (Arm 1)}

The information-only control group (arm 1) features a streamlined version of the intervention app that provides all the informational content of the Resources section (Figure 3), HIV or viral load test kit ordering and tracking (Figure 4), and access to the care navigator. Our design of the control arm balances equipoise with the research study design; in the HMP 1.0 trial, information-only control arm participants also experienced a statistically significant intervention benefit [58]. We have considered this effect in our sample size calculations.

Figure 3. Example informational article screenshots from HealthMpowerment (HMP) 2.0 resources feature.

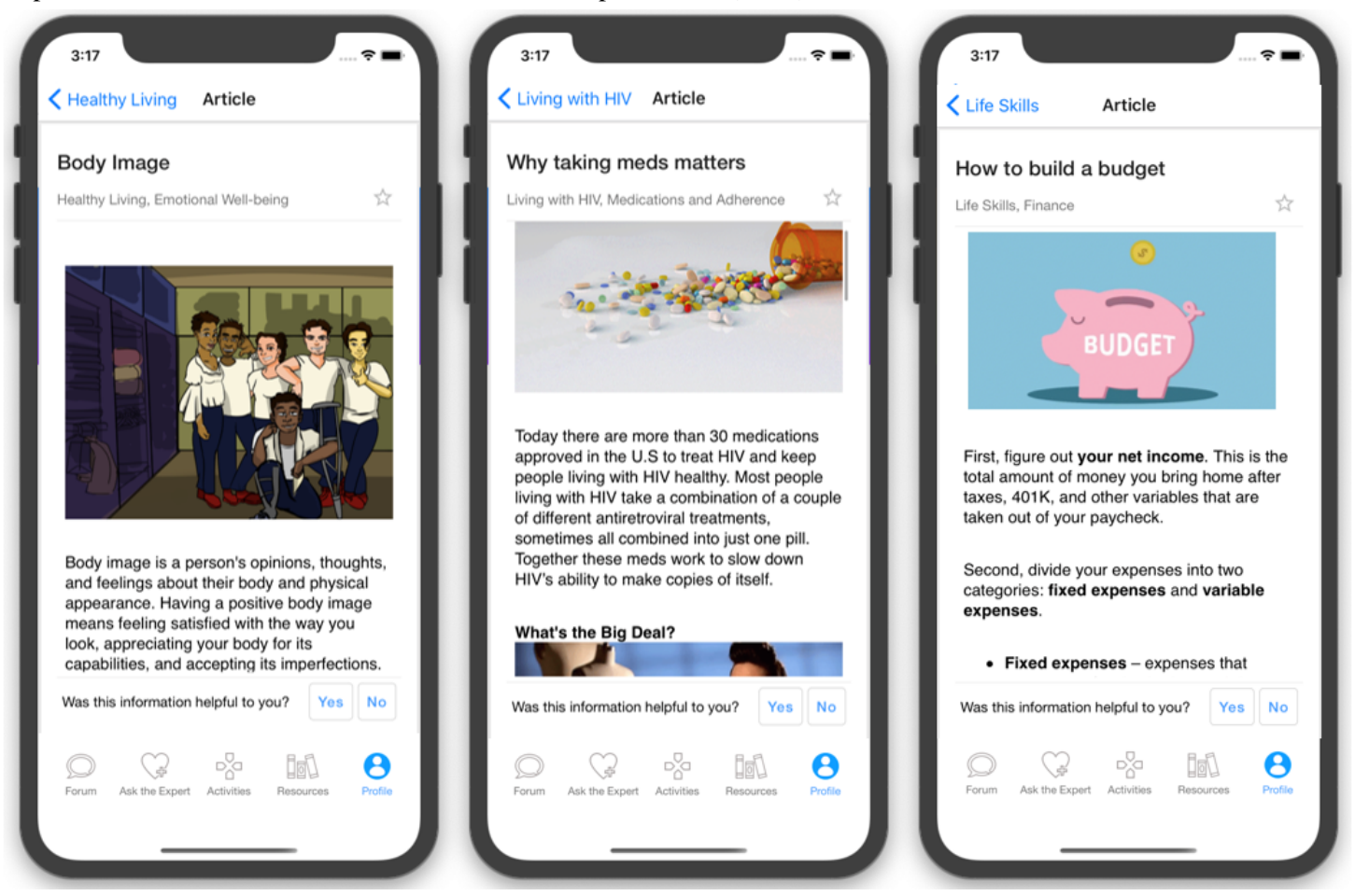

Figure 4. Example screenshots of the HealthMpowerment (HMP) $2.0 \mathrm{HIV}$ and HemaSpot self-test kit features.

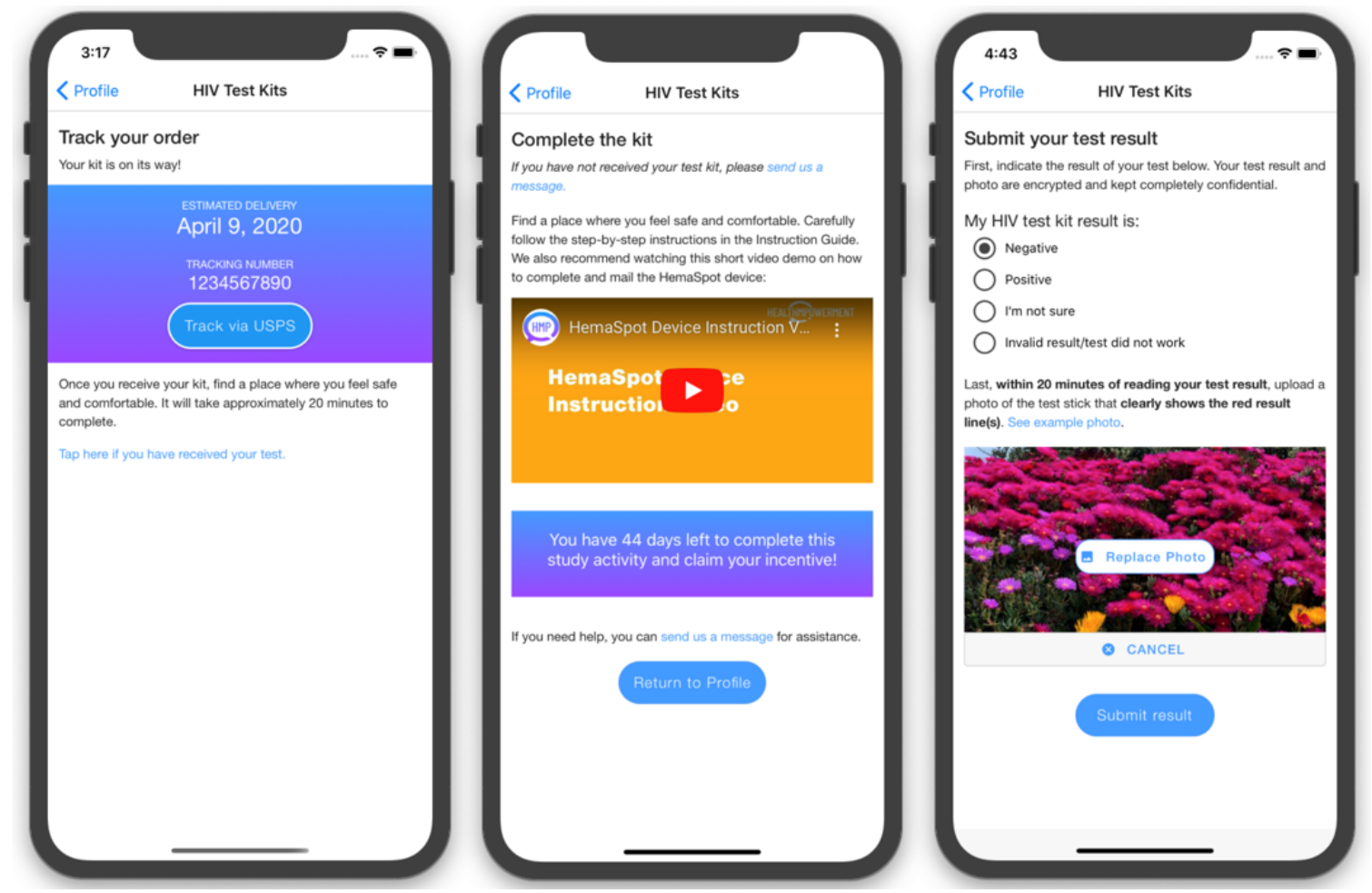




\section{Researcher-Created Network Intervention (Arm 2)}

Eligible, enrolled participants who are randomized to the researcher-created network intervention ( $\operatorname{arm} 2$ ) will have access to all features of HMP 2.0 (Table 1). These features include those described earlier and forums where participants can start or contribute to conversation threads and polls (Figure 5); an anonymous question and answer platform (Ask an Expert) where participants submit questions that are answered by a health care provider (Figure 6); a profile page that participants can personalize (Figure 7); an activity center supporting interactive learning, skill building, goal setting, and decision making (Figure 8); and a badge center with reward levels for all forms of engagement within the app (Figure 9).

Figure 5. Example Forum conversation screenshots from HealthMpowerment (HMP) 2.0 intervention arms feature.

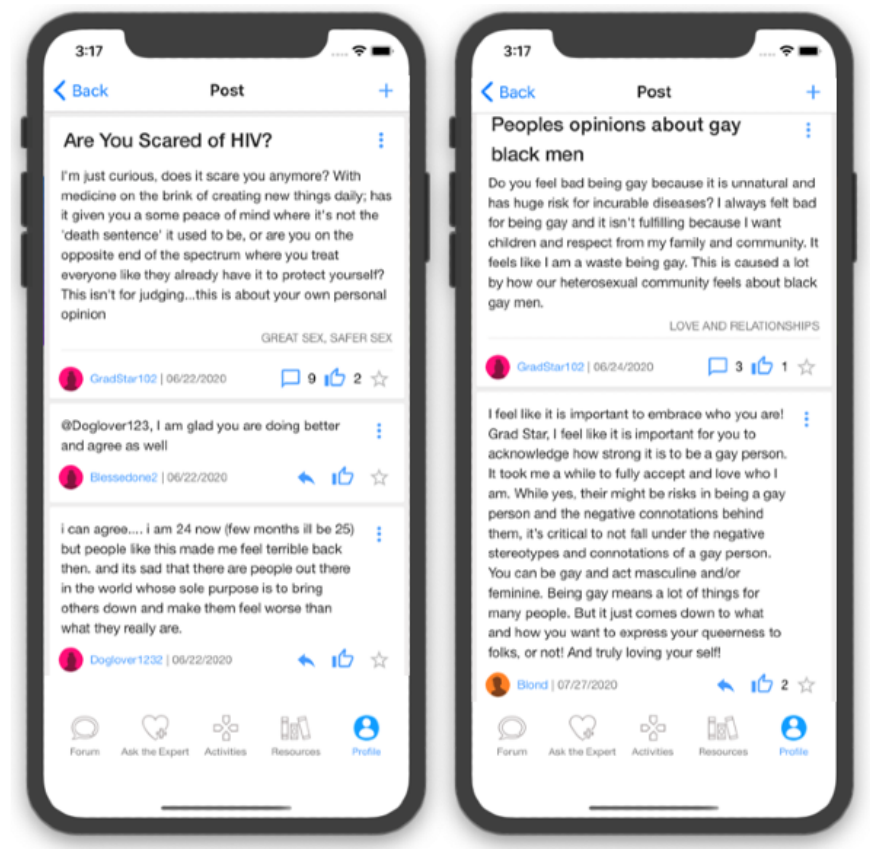

Figure 6. Example Ask the Expert screenshots from HealthMpowerment (HMP) 2.0 intervention arms feature.

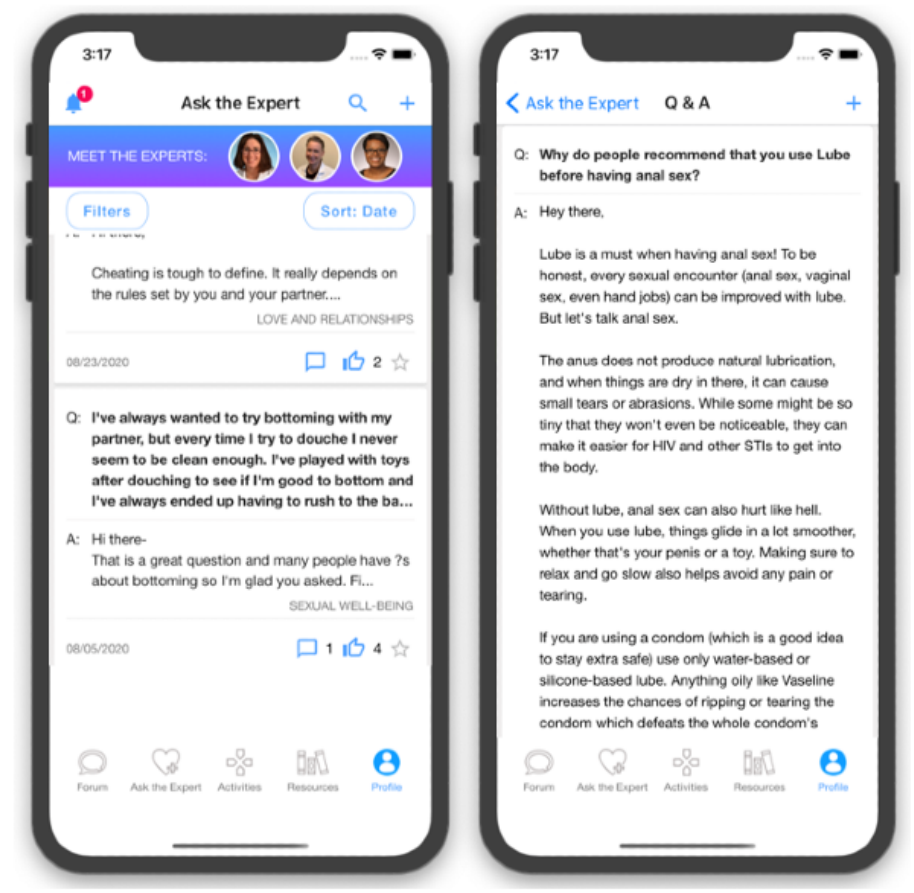


Figure 7. Example screenshots from avatar and personalized profile for HealthMpowerment (HMP) 2.0 intervention arms.

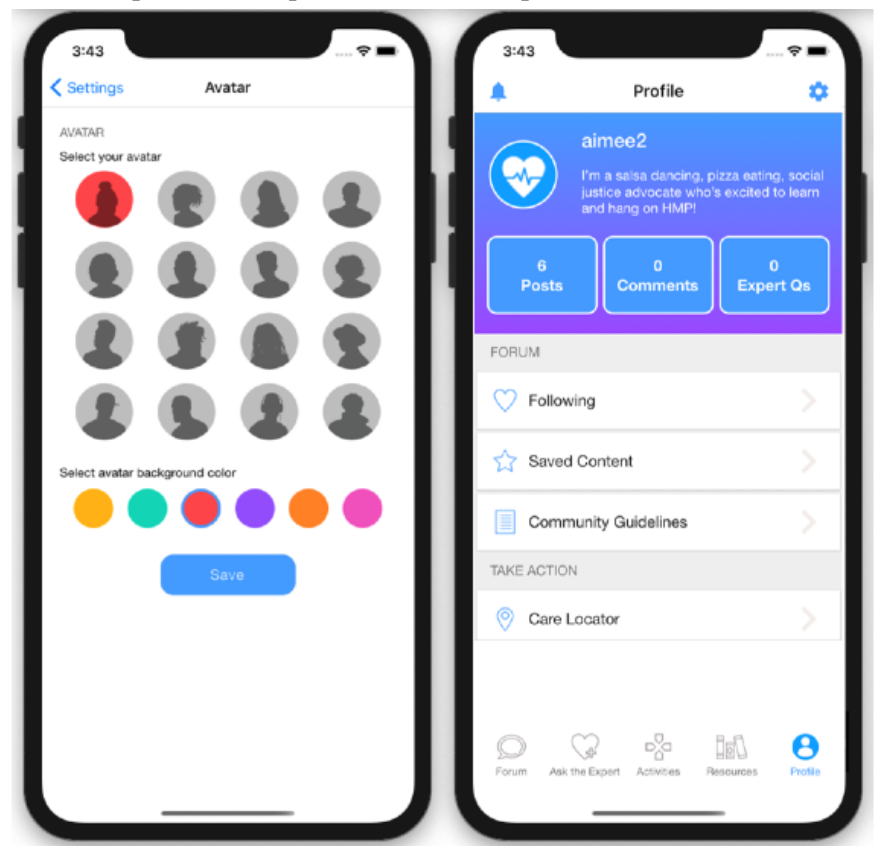

Figure 8. Example screenshots of decision-making activities in the HealthMpowerment (HMP) 2.0 intervention arms.

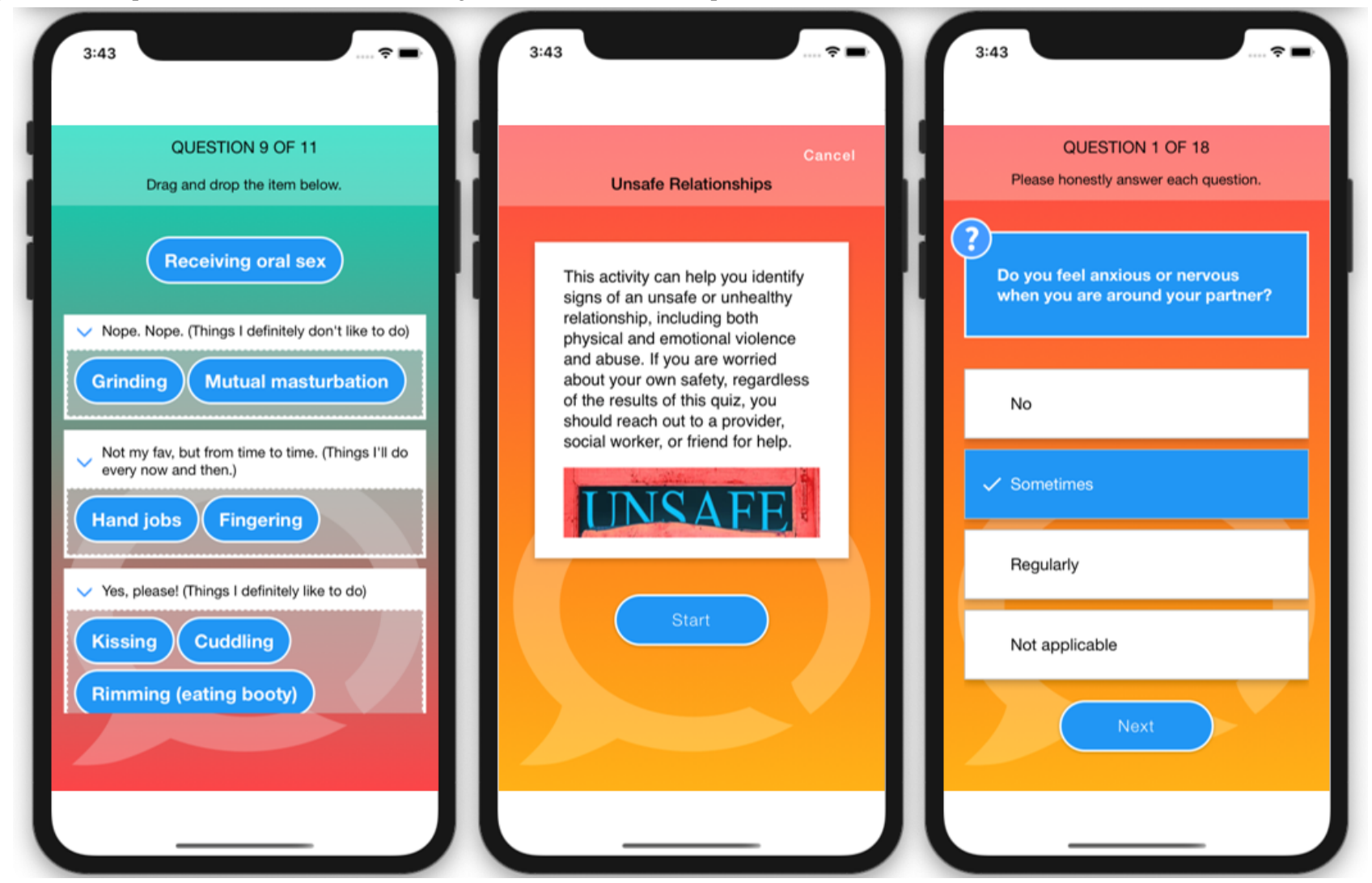


Figure 9. Examples of badges HealthMpowerment (HMP) 2.0 intervention arms participants can earn within the app.

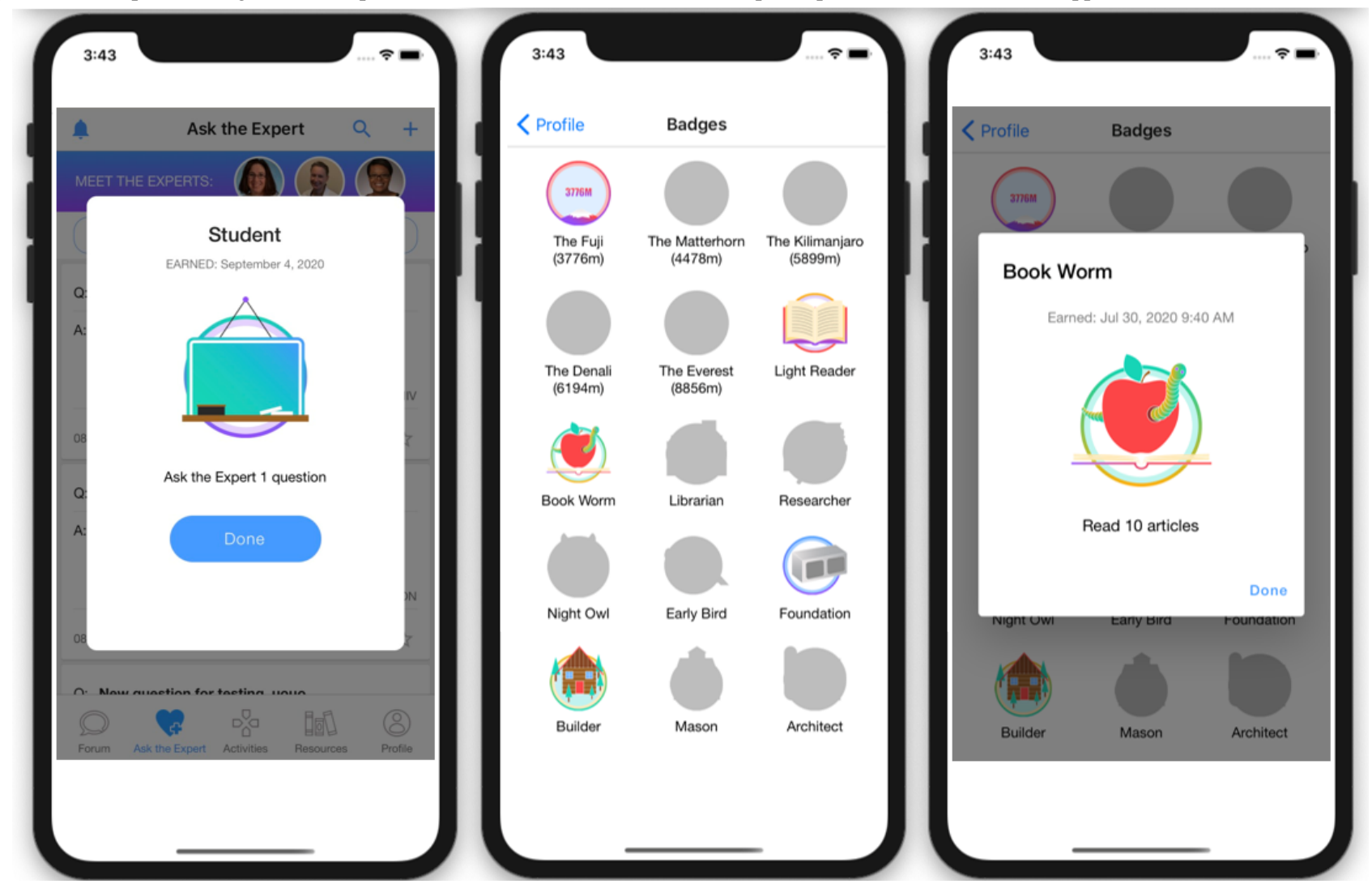

\section{Peer-Referred Network Intervention (Arm 3)}

Participants randomized to arm 3 will be enrolled into a separate, parallel version of the HMP 2.0 full-feature intervention with access to all the features described for arms 1 and 2. However, participants in arm 3 can also share a customized invitation for peers to join the study (Figure 10) [99]. Participants may continue to send invitations to peers up until their 90th study day or until 2 of their referred peers have screened eligible and enrolled in the study. At that point, the participant's app will display a message to them that they have reached their peer referral quota and their referral button will be deactivated. In the app, participants in arm 3 can see the usernames of their referred peers but no other information about these individuals. Enrolled peers will see the username of their referrer but will not be eligible to refer peers themselves. 
Figure 10. Example screenshots of peer referral feature from HealthMpowerment (HMP) 2.0 intervention arm 3.

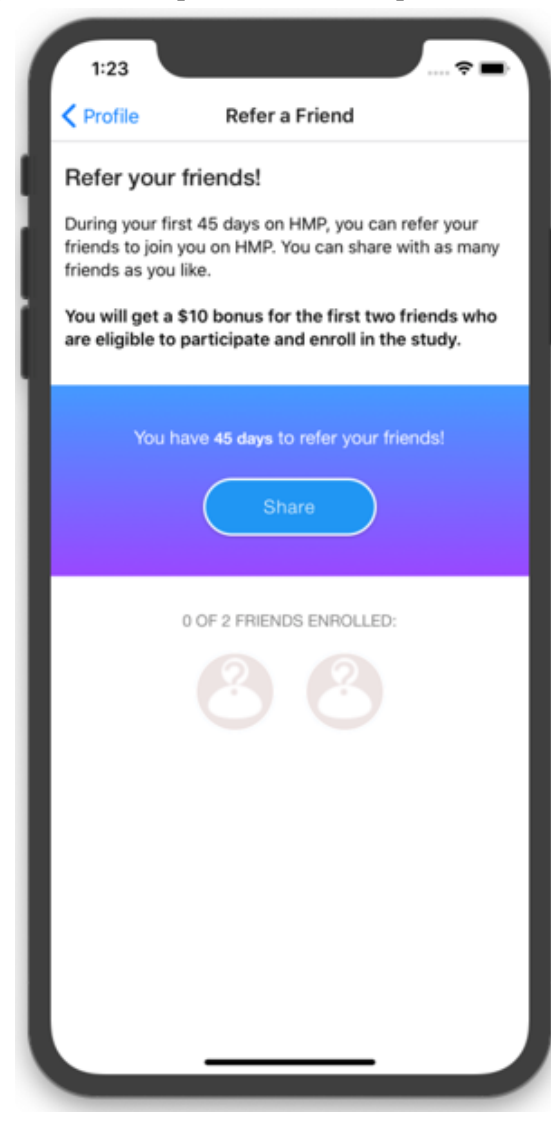

\section{HMP 2.0 Care Navigator}

HMP 2.0 provides all study arm participants access to a trained care navigator who will use existing web-based databases of resources to connect participants to trusted HIV testing and care services in their communities as needed and auxiliary resources such as behavioral health services, housing assistance programs, and food assistance programs. Within the study intervention arms (2 and 3), the care navigator will also monitor the forum and Ask an Expert health care provider platform. During all study years, the care navigator will work closely with the YAB to elicit additional content to support emerging stigmas, service-related needs, and concerns among YBLMT that can be integrated into the intervention.

\section{Home Collection of Blood and Saliva for Viral Load and HIV Testing}

At baseline, 6, and 12 months, HIV-positive participants, across all study arms, who provide valid mailing addresses will be sent a HemaSpot-HF kit (Figure 11). The kit contains (1) one HemaSpot-HF device (Figure 12) and an instructional booklet on how to properly collect a blood specimen (eighth-grade reading level) with a link to a web-based step-by-step video; (2) a return envelope addressed to the lab with postage; (3) a lab sheet that includes the participant's unique identification number; and (4) all materials needed to collect the blood specimen in a safe and sanitary way: alcohol pads, 2 retractable 18-gauge fingerstick safety lancets, gauze pads, adhesive bandages, and a biohazard bag. 
Figure 11. Image of participant informational package insert depicting the HemaSpot-HF blood collection kit contents.

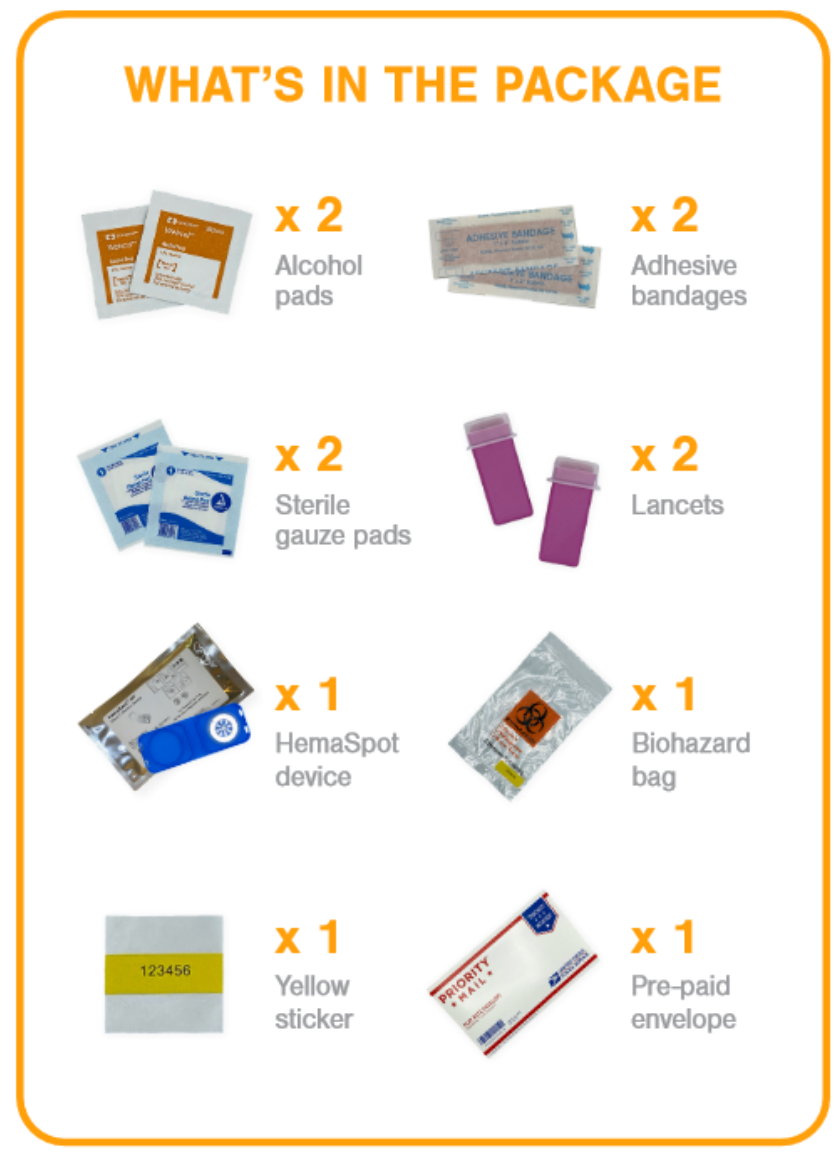

Figure 12. Two HemaSpot-HF blood collection devices (open and closed).

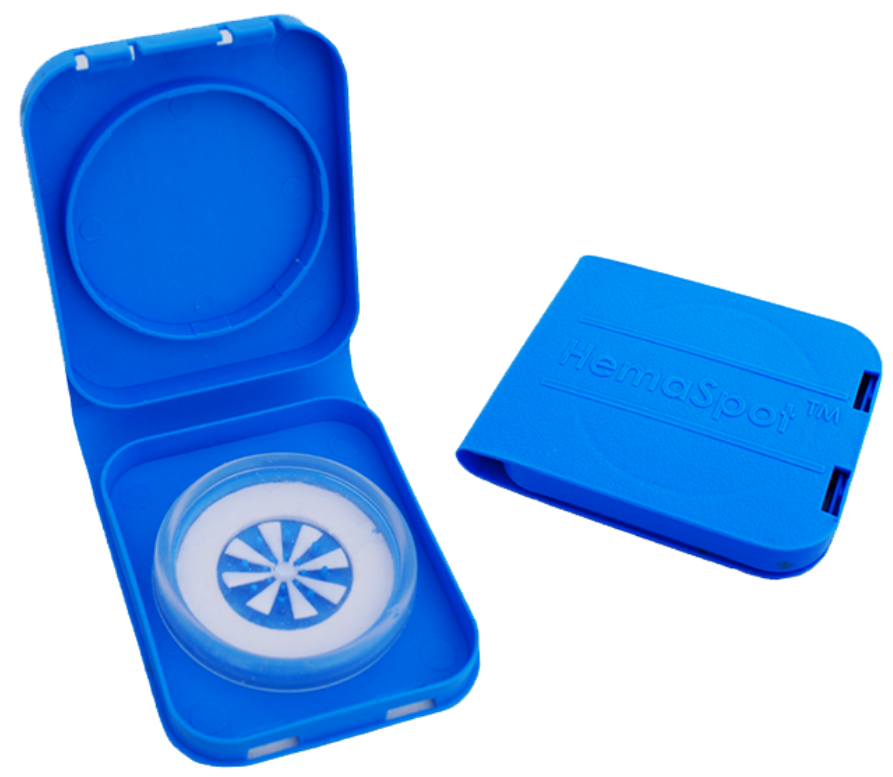

HemaSpot-HF was developed to address technical issues associated with using traditional filter cards for dried blood spot collection [100]. Research by our team members found that men living with HIV are willing and able to collect their own blood specimens using HemaSpot-HF and may prefer this option over blood draws at clinic-based study visits as it offers convenience and privacy $[101,102]$. HemaSpot-HF is a small plastic device, about the size of a credit card and 0.25 inches deep. Specimens can be stored at room temperature, making HemaSpot-HF amenable to home self-collection. After blood collection (3-5 drops) with a single-use retractable safety lancet, HemaSpot-HF can be closed and shipped immediately because a desiccant in the kit quickly dries the sample inside the cartridge. Participants mail their completed kits directly to the study laboratory using a prepaid return envelope. Laboratory staff will track and store packages and test samples in batches 
according to their internal protocol. Participants will be informed that testing is for research purposes only and that the results of their HemaSpot-HF viral load test will not be returned to them given that we cannot guarantee clinically accurate results for individual participants because of time lags from shipment and batched specimen processing. Study staff will recommend that participants visit their regular HIV care providers or work with care navigators to access providers to obtain current HIV viral load test results.

Self-reported HIV negative or status unknown participants across all study arms can request up to 3 in-home OraQuick (R) HIV tests (oral self-swab) [103] over the course of the 12-month study. Kit requests are made via the app and are sent in a discreet, unmarked box. These rapid tests are optional and help to maintain equipoise with the viral load collection procedures with HIV-positive counterparts in the trial. We will ask participants to take a picture of their test stick that shows their test result and then upload it securely through the intervention app. In post hoc analyses, we will compare those who request home test kits with those who report traditional testing in the follow-up assessments. If a participant reports a new HIV-positive result (whether through home test kit testing results, through an HIV status change in their follow-up surveys, or by notifying the study team), the care navigator will reach out to them following a prespecified protocol to support them in making an appointment for confirmatory testing and linkage to local HIV care.

\section{Participants and Enrollment Procedures}

Eligible participants will be those assigned male sex at birth (no restrictions on current gender identity), aged 15 to 29 years (inclusive) at the time of screening, identify as Black, African American, Latinx or Hispanic, be a resident of the United States (verified by zip code), report at least one episode of CAI with men or TW in the previous 6 months or recruited from a partner-seeking app (eg, Grindr, Jack'd), and report having regular access to a smartphone device to access the HMP 2.0 app. Individuals who are recruited by participants assigned to the peer-referred intervention arm (arm 3) will have comparable eligibility criteria, with the exception that referred peers can identify as any race or ethnicity. Those who report testing HIV positive and having hemophilia or are currently taking anticoagulant medications will be excluded because of the risk of harm posed by the self-collected blood sampling.

The decision to include MSM and TW and Black and Latinx participants in the same study was decided early in the study design after much thought. We recognize that the experiences of stigma and discrimination manifest differently among MSM and TW communities, Black and Latinx populations, and communities living with, or affected by, HIV. Consistent with our intersectional framing, we value and acknowledge that the resultant combinations of these subgroups are even more different. In our formative study, however, we discovered that sharing these diverse experiences can bring people together to talk about these experiences and engage in inclusive dialogue that fosters support. Creating a space for open dialogue and learning facilitates individuals' learning from each other's differences and working through issues of stigma and discrimination they may be experiencing within the lesbian, gay, bisexual, transgender, queer community. Furthermore, some youths may still be establishing and learning about their various identities; HMP provides a safe space for broader exposure and learning, including welcoming youths who are uncertain about their sexual orientation or gender identity. Therefore, we decided that the benefits of being more inclusive in the context of this intervention outweighed the drawbacks of being more limited or targeted. All study arms have tailored content inclusive of variety in gender identity, gender expression, and sexual orientation. Similarly, the YAB and study team were attentive to include imagery and visual representations in the app that depicted diversity of gender, race and ethnicity, culture, and sexual expression. Participant avatar options feature a range of colors, hairstyles, and face shapes (Figure 7).

We will reach the study population using targeted advertisements based on sociodemographic characteristics on social media sites, including Facebook, Tumblr, Instagram, Black Gay Chat Live, Jack'd, Grindr, and Scruff, and through clinic referrals and participant repositories. Recruitment sites and materials have been developed alongside our YAB. Each study advertisement includes a unique link for interested individuals to complete the study screener, where they may verify their eligibility or contact the study team by email or a toll-free number (Figure 13). 
Figure 13. Example Facebook social media study advertisements for HealthMpowerment (HMP) 2.0 trial.

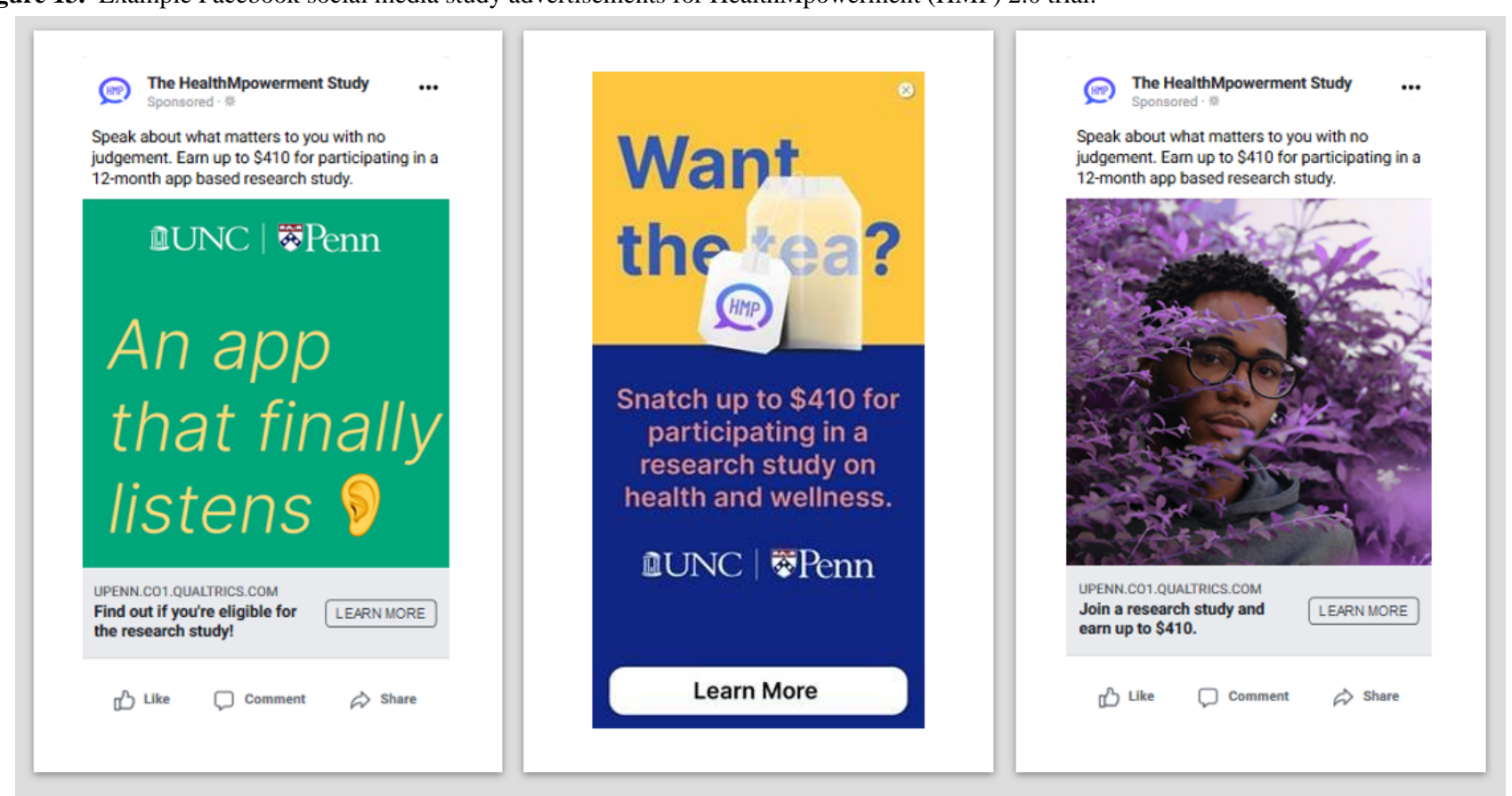

We aim to enroll approximately 20 to 30 participants per month; this staggered design will allow time for the social networks to develop within the intervention. We will monitor recruitment and enrollment efforts weekly, including examining which specific study advertisements and recruitment methods (eg, social media, clinic referrals, participant repositories) generate the most enrolled participants and the characteristics of the enrolled sample. This will allow us to adapt our recruitment strategies as needed to ensure a diverse sample across age and geographic area.

The web-based, self-administered study screener explains the HMP 2.0 trial, the screening process, and confidentiality and privacy of all personal information and collects consent to complete screening. Data from those who screen eligible are reviewed biweekly for signs of fraud [104]. Individuals who pass these data checks are invited to enroll in the study. The enrollment procedures begin with an electronic informed consent form. Consented participants are then directed to a 45-min baseline survey and subsequently allocated to 1 of the 3 study arms using our HIV-stratified randomization procedure. Participants who are ineligible or do not consent are thanked and rerouted to a public site (eg, Google). A second data quality check is completed comparing select baseline and screener responses, and those who pass are sent a unique access code and directions for downloading the study app from either the Google Play or Apple app store (Figure 1).

\section{Sample Size}

We will enroll a total of 1050 participants from across the United States. Our sample size calculations were on the basis of pairwise HIV-stratified comparisons of the 3 groups in terms of the proportion of successful engagement using a two-sided significance level of 0.05 , adjusted by the number of comparisons using a Bonferroni adjustment (significance level is 0.017 for 3 comparisons) and a minimum power of $80 \%$. To achieve $80 \%$ power to detect a minimum effect size (odds ratio
[OR] 1.9) of successful engagement in care between the 3-arm trial while maintaining the overall type I error rate at 5\%, we will require at least $450 \mathrm{HIV}$-negative and $450 \mathrm{HIV}$-positive participants to detect a $17 \%$ difference. In the event of a $20 \%$ loss to follow-up, we will have sufficient power to detect an OR 2.1 (18\% difference) at $\alpha=.017$. Participants may continue the study even if they miss an assessment intermittently. We will compare those who completed different follow-up surveys with those who did not on key baseline predictors to check for possible sampling bias. Our analysis will use intent to treat as appropriate. The primary outcome for the proposed trial is stratified by HIV status and defined as successful engagement in care. We define power as identifying the difference in the proportions of YBLMT with sero-specific engagement in HIV care within 12 months of each of the 2 intervention arms (arm 2 researcher-created network and arm 3 peer-referred network) compared with the control arm (arm 1 information-only control), and between the 2 intervention arms 2 and 3 . We have not set stratifications by gender, sexual orientation, race or ethnicity-it is set only by HIV status. We are proactively recruiting through transfocused health and community-based organizations and networks, and recruitment materials contain a variety of body images and expressions of gender and sexuality. On the basis of prior studies, we anticipate having at least $10 \%$ of our sample to identify as transgender. We will compute a post hoc power analysis to calculate the observed power to provide context for our findings for any subgroup analyses.

We will also select a purposive subsample of 45 enrolled participants ( 5 from the control arm; 20 from each intervention arm) across different demographic and intervention engagement profiles to complete qualitative evaluation interviews via a Health Insurance Portability and Accountability Act-compliant videoconferencing platform. A study team member will conduct interviews following a semistructured guide focused on overall intervention satisfaction, the intervention's perceived impact on stigma and HIV outcomes, and participants' evaluations of 
the social networking features (intervention arms only). Control arm participants are included in the interviews, as we expect the information-only intervention will also show a modest impact. Half of the interviews will be conducted at month 6 and half at month 12 to better understand intervention use over time and to reduce survivor's bias of only interviewing participants who are retained for 12 months. Interviews will last 30 to 45 min, will be audio recorded with the participant's consent, and will be transcribed.

\section{Randomization}

Participants will be allocated to the 3 study arms using a computer-generated block randomization, with stratification by HIV status. For the HIV-negative stratum $(n=300,2$ treatment groups), the randomization scheme consists of 18 blocks of 8 subjects and 26 blocks of 6 subjects. Similarly, for the HIV-positive stratum ( $\mathrm{n}=450,3$ treatment groups), the randomization scheme consists of 20 blocks of 9 subjects and 45 blocks of 6 subjects.

\section{Engagement and Retention}

In the HMP 1.0 trial, participants who remained more engaged in the intervention had greater improvements in study outcomes [58]. Thus, HMP 2.0 uses multiple strategies to promote sustained participant engagement. First, we expanded the most highly rated and frequently used features of HMP 1.0 (Forum, Ask an Expert, Resources, and Quizzes). Second, we converted the points-based reward system (which was not highly rated by participants) to a system where participants earn virtual badges for completing activities and meeting milestones within the app. We have used a similar badge system within 2 other intervention apps that young MSM have rated with high acceptability $[105,106]$. Third, we will follow a schedule of releasing new content onto the app each week, including activities, polls, articles, and regular YAB posts. Each month, we will also send an electronic newsletter tailored for intervention arms 2 and 3 that highlights new content, poll results, spotlight profiles for YAB and study staff, and the month's most popular app discussions and articles. For overall study retention, we will follow a protocol schedule of connecting with all participants via push notifications, in-app notifications, text messages, emails, and phone calls. These will consist of preprogrammed prompts triggered after 14,30 , and 60 days of no app log-in or missed study milestone, and tailored communications from study staff.

\section{Incentives}

Depending on the participant's study arm and the activities they complete, they may receive between US \$390 and US \$410 in e-gift cards for participating in all aspects of this study (Table 2). All participants can receive up to US $\$ 280$ in e-gift cards for completing surveys at baseline, 3, 6, 9, and 12 months, with a US $\$ 50$ bonus for completing at least 4 of the 5 surveys. On the basis of HIV status, participants may complete up to 3 in-home HIV tests or HIV viral load kits. Participants will receive US \$20 for each (US \$60 total over the 12-month study period) if they report the result of the HIV in-home test or if they complete and return the HIV viral load kits. Peer referral group participants ( $\operatorname{arm} 3$ ) can receive up to US \$20 for referring eligible friends to the study: US $\$ 10$ for each friend that is referred and enrolled in the study within the first 45 days. A subsample of 45 participants who are selected to complete a qualitative evaluation will receive a US \$50 incentive. Incentives for completing an HIV self-test were kept intentionally low (US \$20) to reduce the influence of the financial incentive driving the behavior. A critical component of the intervention is raising health awareness and individual empowerment for one's sexual health and behaviors; thus, the incentive is a nudge to repeat the desired behavior every 3 months and is not the primary motivator.

Table 2. Schedule of HealthMpowerment 2.0 randomized controlled trial study incentives (US \$).

\begin{tabular}{|c|c|c|c|c|c|c|c|}
\hline Activity & Eligible participants & Baseline & 3 months & 6 months & 9 months & 12 months & $\geq 4$ surveys bonus \\
\hline Complete survey & All & 50 & 35 & 50 & 35 & 60 & 50 \\
\hline Return HemaSpot kit & HIV positive & 20 & $\mathrm{~N} / \mathrm{A}^{\mathrm{a}}$ & 20 & N/A & 20 & N/A \\
\hline Upload HIV test result ${ }^{\mathrm{b}}$ & HIV negative and unknown & 20 & N/A & 20 & N/A & 20 & N/A \\
\hline Referred peer enrolls ${ }^{c}$ & Arm 3 & 20 & N/A & N/A & N/A & N/A & N/A \\
\hline In-depth interview & Subset of 45 across all arms & N/A & N/A & 50 & 50 & 50 & N/A \\
\hline
\end{tabular}

${ }^{\mathrm{a}} \mathrm{N} / \mathrm{A}$ : not applicable (not all incentives are relevant for all study time points).

${ }^{\mathrm{b}} \mathrm{HIV}$ self-tests may be ordered any time during the 12-month window, up to 3 times, at least three months apart.

${ }^{\mathrm{c}}$ US $\$ 10$ per enrolled peer for up to 2 peers. Peer enrollment must be completed within the first 90 days following the referring participant's enrollment.

\section{Outcomes}

\section{Primary Outcomes}

Following our theoretical premise that similar stigma-related barriers impact both HIV prevention and care behaviors, we aimed to define a primary outcome of engagement in care with parallel behaviors across HIV status. For HIV-positive participants, we define successful engagement in HIV care as consistent VS across the 12-month trial (per Institute of Medicine guidelines [107]). We will ask self-reported recent (past 3 months) VS status at baseline and each follow-up assessment. Completed HemaSpot-HF kits will provide viral load biomarker data for baseline and months 6 and 12. For HIV-negative or sero-unknown participants, we define successful engagement in care as participation in routine HIV testing ( 2 or more HIV tests at least three months apart, per United States Centers for Disease Control and Prevention 
guidelines [108]). We will also examine the proportions of participants who complete at least one HIV test in the 12-month period and assess whether this is an appropriate parallel measure based on self-reported risk behaviors. Additional analyses will assess appointment and medication adherence (HIV-positive participants), uptake and maintenance of PrEP (HIV-negative participants), and testing and diagnoses for sexually transmitted infections.

\section{Mediators of Intervention Effects}

The secondary objective is whether participant engagement mediates the intervention effects observed in stigma and HIV care outcomes. Temporal engagement will be measured by examining participants' number of log-ins to the app and total length of time in the app as calculated by time stamps at each log-in and logout or app timeout. We will also calculate scores for all intervention arms participants on the basis of their levels of active (posting and commenting) and passive (reading) engagement. Active engagement scores will be calculated by assigning one point for each instance a participant posted or commented on site content. Passive engagement scores will be calculated using paradata to determine the number of times they read content and then assigning one point per read. Aggregate engagement scores for each participant will be included as indicators and latent factors, as appropriate, in our analyses. This strategy will allow us to examine how different forms of engagement (eg, temporal engagement, active engagement, passive engagement) influence our study outcomes. The core measures of app engagement are included in Table 1.

An additional mediation analysis of interest is how changes in stigma and improvements across the HIV care continuum vary between the researcher-created versus peer-referred social network intervention conditions.

\section{Covariates}

We will measure the following constructs as potential predictors or moderators: sociodemographics (race, ethnicity, education, employment, place of birth, housing status, and history of incarceration, sexual identity, and outness to social network), substance use, psychological distress (depression and anxiety symptoms), intervention acceptability and use over time, use of technology and social media, and eHealth literacy [109]. These measures are included in Table 3. 
Table 3. Study measures for HealthMpowerment 2.0 randomized controlled trial.

\begin{tabular}{|c|c|}
\hline Variables and scale & Items \\
\hline \multicolumn{2}{|l|}{ Primary outcomes } \\
\hline Viral suppression $(\mathrm{HIV}+)$ & 2 \\
\hline Consistent HIV testing (HIV-) & 2 \\
\hline \multicolumn{2}{|l|}{ Secondary outcomes } \\
\hline Appointment adherence [110] & 2 \\
\hline Wilson adherence scale $(\mathrm{HIV}+)$ [111] & 3 \\
\hline PrEP $^{\mathrm{a}}$ uptake (HIV-) [112] & 8 \\
\hline $\mathrm{STI}^{\mathrm{b}}$ testing and infections & 3 \\
\hline \multicolumn{2}{|l|}{ Experienced stigma } \\
\hline Enacted or personalized HIV stigma scale, adapted $[113,114]$ & 12 \\
\hline Gender minority stress and resilience-rejection subscale [115] & 6 \\
\hline Every day discrimination scale $[116,117]$ & 20 \\
\hline \multicolumn{2}{|l|}{ Internalized stigma } \\
\hline Negative self-image HIV stigma scale, adapted [114] & 7 \\
\hline Internalized homophobia scale—revised [118] & 4 \\
\hline \multicolumn{2}{|l|}{ Anticipated stigma } \\
\hline Anticipated HIV stigma scale, adapted [114,119] & 8 \\
\hline Every day discrimination scale $[116,117]$ & 20 \\
\hline \multicolumn{2}{|l|}{ Challenging stigma } \\
\hline Sense of community and self-identity & 20 \\
\hline Stigma resistance scale, adapted [120] & 16 \\
\hline \multicolumn{2}{|l|}{ Contextual mechanisms } \\
\hline Social support (select PROMIS ${ }^{\mathrm{c}}$ measures) [121] & 8 \\
\hline Social isolation (select PROMIS measures) [121] & 8 \\
\hline Depression $\left(\mathrm{PHQ}-8^{\mathrm{d}}\right)$ [122] & 8 \\
\hline Anxiety $\left(\mathrm{GAD}^{\mathrm{e}}-7\right)[123]$ & 7 \\
\hline Medication adherence self-efficacy $\left(\right.$ HIV-ASES $\left.^{\mathrm{f}}\right)$ [124] & 9 \\
\hline Self-esteem [125] & 10 \\
\hline \multicolumn{2}{|l|}{ Covariates } \\
\hline Demographics and socioeconomic characteristics & 25 \\
\hline Substance use $\left(\mathrm{ASSIST}^{\mathrm{g}}\right.$ ) [126] & 4 \\
\hline PrEP use & 5 \\
\hline Sexual behavior $[127,128]$ & 35 \\
\hline Technology use $[129,130]$ & 24 \\
\hline
\end{tabular}

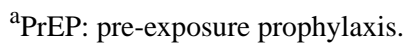

${ }^{\mathrm{b}} \mathrm{STI}$ : sexually transmitted infection.

${ }^{c}$ PROMIS: patient-reported outcomes measurement information system.

${ }^{\mathrm{d}}$ PHQ-8: eight-item patient health questionnaire.

${ }^{\mathrm{e}} \mathrm{GAD}$ : generalized anxiety disorder.

${ }^{\mathrm{f}}$ ASES: adherence self-efficacy.

${ }^{\mathrm{g}}$ ASSIST: alcohol, smoking, and substance involvement screening test. 


\section{Statistical Analysis}

\section{Quantitative Evaluation}

Clinical and demographic characteristics will be described for the entire sample and by treatment group. We will use both graphical (box-plots and histograms) and descriptive (mean, $\mathrm{SD}, \mathrm{IQR}$ for continuous variables, and frequency distribution for categorical variables) approaches to describe our sample.

These will be compared with treatment groups using the analysis of variance or Kruskal-Wallis test for continuous variables and chi-square test for categorical variables. We will conduct primary analyses of our successful engagement in care outcome (month 12 status) using logistic regression models to compare each active intervention treatment group (arms 2 and 3) with the control group (arm 1) in pairwise comparison tests at an adjusted significance level of 0.017 to reduce type I errors in our 3-arm trial. This approach allows us to also test for differential efficacy between the 2 intervention conditions (ie, does the peer-referral intervention arm 3 outperform the researcher-created intervention arm 2?).

We will use the general framework of generalized linear mixed models $[83,84,131]$ to model these longitudinal outcome trajectories [132-134]. Given that some of our outcomes are binary, some count and some continuous traits will be treated differently (identity for continuous outcome, logit for binary outcome, and natural $\log$ for count outcomes). Logistic regression analyses will be stratified by serostatus. The regression will be run with group assignment only in the model. Among HIV-positive participants, we will examine how intervention conditions influence YBLMT's likelihood of consistent VS over 12 months. We will also test intervention effects on retention in care per Institute of Medicine guidelines (ie, proportion of HIV-positive participants who obtain at least two viral load tests [at least three months apart] within 12 months). For HIV-negative participants, we will compare the proportion of participants who obtain at least two HIV tests (at least three months apart) within 12 months across arms. Estimates will be calculated and presented with corresponding $95 \%$ exact binomial CIs.

Building on our theoretical framework, we will use structural equation modeling to test whether engagement with researcherand participant-generated stigma content predicts changes in stigma-related outcomes over time (eg, decreases in anticipated HIV stigma) and changes in HIV care outcomes over time (eg, repeat HIV testing; consistent VS). In these HIV-stratified analyses, we will use latent class analysis to characterize participants' engagement in the site. We will estimate the independent contributions of passive and active engagement on both stigma and HIV outcomes and how cumulative engagement in stigma-related discussions influences these outcomes. Key sociodemographic predictors will be included as covariates (eg, age, time since diagnosis). We will also conduct exploratory stratified analyses by race, ethnicity, and gender.

\section{Qualitative Evaluation}

Expanding on the procedures developed and successfully employed in HMP 1.0 [92], we will conduct a mixed methods analysis of participant-contributed content to the forums. All content and associated paradata of each post will be captured by the intervention database. We will use qualitative data analysis software to catalog and code all instances of stigma-related content and characterize their potential contributions to HIV risk and care behaviors. First, 2 coders will independently identify all posts that contain stigma-relevant content. Next, they will conduct a content analysis to categorize the nature of the coded stigma content as enacted, community, anticipated, internalized, or challenged stigma. Coding discrepancies will be reviewed and resolved by a third analyst. Ongoing analysis progress will be discussed during biweekly YAB meetings and feedback sought on YAB members' interpretations of participant forum conversations and emergent themes. The final coded data set will be used for qualitative analyses and publications, and to create variables that quantify participants' engagement with each type of stigma-related domain. These data will be used to examine how frequency of engagement with stigma content is associated with changes across HIV outcomes directly and through proposed mediators (eg, social support and isolation, substance use, depression). We successfully used this methodology and established analytic protocols to carry out these procedures $[66,67,92]$.

For the qualitative analyses of the 45 interviews, we will create a codebook of a priori and emergent themes, including operational definitions of all codes and sample quotations, to illustrate how to apply each code. Two study team members will use the codebook to independently code the data, whereas a third team member will review these coded sections and resolve discrepancies. We will use qualitative data analysis software and matrices to assist with theme identification, coding textual data, and describing relationships among codes (via code co-occurrence and memoing functions) [135]. Analysis results will be used in conjunction with participants' survey responses, biological outcomes, and usage profiles to present a mixed methods intervention results analysis.

\section{Results}

\section{IRB Approval and Trial Registration}

The research and ethics presented in this study were approved by the IRB of the University of Pennsylvania (829805) as the IRB of Record. Reliance agreements between the University of Pennsylvania, the University of North Carolina Chapel Hill, Duke University, and SUNY Downstate have been completed. A certificate of confidentiality was obtained from the National Institute of Child Health and Human Development, and a waiver of parental consent or assent was obtained for participants aged 15 to 17 years. This study is registered on ClinicalTrials.gov (NCT03678181).

\section{Recruitment and Enrollment}

Study recruitment began on July 20, 2020. As of November 20, 2020, 3780 participants had completed screeners, yielding 830 eligible participants. Among the 218 participants who went on to complete the baseline survey, $94.0 \%$ (205/218) have enrolled and been randomized to a study arm, representing $19.52 \%$ $(205 / 1050)$ of the total target enrollment. Enrolled participants are geographically diverse, representing all 50 contiguous United States and Washington DC, vary in age $(36 / 205,17.6 \%$ aged 
15-19 years; 55/205, 26.8\% aged 20-24 years; and 114/205, $55.6 \%$ aged $25-29$ years), and $18.5 \%$ (38/205) report an HIV-positive status at baseline. Recruitment is anticipated to last through September 2022, with final study follow-up to be completed by September 2023 and results to be available in 2024.

\section{Discussion}

\section{Trial Innovations}

There is a great need and potential to develop, implement, and scale up HIV prevention and care interventions for YBLMT. Implementation barriers and facilitators and analyses from this study will inform the design of mHealth engagement strategies for connecting with YBLMT across the HIV continuum. Our results will further the field's understanding of how engagement with an mHealth intervention that builds on the networks of YBLMT impacts and curtails the role of intersectional stigma in well-being. We are also testing several remote health service intervention components among young people (mail-based self-collected viral load via finger prick, HIV self-testing via oral swab, remote care navigation to confirmatory testing, PrEP, and HIV care) that have previously been tested among an older age range of predominantly White MSM.

\section{Principal Contributions to the Field}

These results will be critically important to the field with the exponential expansion of telehealth and at-home, self-administered biomarker specimen collection and testing. Our projects' tools and framework may inform future mHealth and stigma reduction initiatives for YBLMT.

\section{Acknowledgments}

This work was supported by the National Institute on Minority Health and Health Disparities (multiple principal investigators [mPIs]: JB and KM, R01MD013623). The HMP 1.0 intervention and the mHealth platform were developed through a grant from the National Institute of Mental Health (NIMH; principal investigator: LH, R01MH093275). Data informing revisions for HMP 2.0 were analyzed through a grant from NIMH (mPIs: JB and KM, R21MH105292). MM is also supported by NIMH under award number K01MH118072. The content is solely the responsibility of the authors and does not represent the official views of the funding agency.

\section{Conflicts of Interest}

None declared.

\section{References}

1. Diagnoses of HIV Infection in the United States and Dependent Areas 2018. US Centers for Disease Control and Prevention. 2020. URL: https://www.cdc.gov/hiv/library/reports/hiv-surveillance/vol-31/index.html [accessed 2020-09-03]

2. Magnus M, Kuo I, Phillips G, Shelley K, Rawls A, Montanez L, et al. Elevated HIV prevalence despite lower rates of sexual risk behaviors among black men in the District of Columbia who have sex with men. AIDS Patient Care STDS 2010 Oct;24(10):615-622 [FREE Full text] [doi: 10.1089/apc.2010.0111] [Medline: 20863246]

3. HIV Infection Risk, Prevention, and Testing Behaviors Among Men Who Have Sex With Men-National HIV Behavioral Surveillance, 23 US Cities, 2017. US Centers for Disease Control and Prevention. 2019. URL: https://www.cdc.gov/hiv/ pdf/library/reports/surveillance/cdc-hiv-surveillance-special-report-number-22.pdf [accessed 2020-09-03]

4. Millett GA, Peterson JL, Flores SA, Hart TA, Jeffries WL, Wilson PA, et al. Comparisons of disparities and risks of HIV infection in black and other men who have sex with men in Canada, UK, and USA: a meta-analysis. Lancet 2012 Jul 28;380(9839):341-348. [doi: 10.1016/S0140-6736(12)60899-X] [Medline: 22819656]

5. Muessig KE, Pike EC, Fowler B, LeGrand S, Parsons JT, Bull SS, et al. Putting prevention in their pockets: developing mobile phone-based HIV interventions for black men who have sex with men. AIDS Patient Care STDS 2013 Apr;27(4):211-222 [FREE Full text] [doi: 10.1089/apc.2012.0404] [Medline: 23565925]

6. Quinn K, Dickson-Gomez J, Broaddus M, Kelly JA. 'It's almost like a crab-in-a-barrel situation': stigma, social support, and engagement in care among black men living with HIV. AIDS Educ Prev 2018 Apr;30(2):120-136. [doi: 10.1521/aeap.2018.30.2.120] [Medline: 29688770]

7. LeGrand S, Muessig KE, Pike EC, Baltierra N, Hightow-Weidman LB. If you build it will they come? Addressing social isolation within a technology-based HIV intervention for young black men who have sex with men. AIDS Care 2014;26(9):1194-1200 [FREE Full text] [doi: 10.1080/09540121.2014.894608] [Medline: 24617609]

8. Bauermeister JA. Romantic ideation, partner-seeking, and HIV risk among young gay and bisexual men. Arch Sex Behav 2012 Apr;41(2):431-440 [FREE Full text] [doi: 10.1007/s10508-011-9747-z] [Medline: 21394660]

9. Phillips G, Birkett M, Hammond S, Mustanski B. Partner preference among men who have sex with men: potential contribution to spread of HIV within minority populations. LGBT Health 2016 Jun;3(3):225-232 [FREE Full text] [doi: 10.1089/lgbt.2015.0122] [Medline: 26907954]

10. Reisner SL, Jadwin-Cakmak L, White Hughto JM, Martinez M, Salomon L, Harper GW. Characterizing the HIV prevention and care continua in a sample of transgender youth in the US. AIDS Behav 2017 Dec;21(12):3312-3327 [FREE Full text] [doi: 10.1007/s10461-017-1938-8] [Medline: 29138982] 
11. Gamarel KE, Nelson KM, Stephenson R, Santiago Rivera OJ, Chiaramonte D, Miller RL, Adolescent Medicine Trials Network for HIV/AIDS Interventions. Anticipated HIV stigma and delays in regular HIV testing behaviors among sexually-active young gay, bisexual, and other men who have sex with men and transgender women. AIDS Behav 2018 Feb;22(2):522-530 [FREE Full text] [doi: 10.1007/s10461-017-2005-1] [Medline: 29214408]

12. Darrow WW, Montanea JE, Gladwin H. AIDS-related stigma among Black and Hispanic young adults. AIDS Behav 2009 Dec;13(6):1178-1188. [doi: 10.1007/s10461-009-9601-7] [Medline: 19680800]

13. Brewer R, Hood KB, Moore M, Spieldenner A, Daunis C, Mukherjee S, et al. An exploratory study of resilience, hiv-related stigma, and HIV care outcomes among men who have sex with men (MSM) living with HIV in Louisiana. AIDS Behav $2020 \mathrm{Jul}$;4(7):2119-2129. [doi: 10.1007/s10461-020-02778-5] [Medline: 31916097]

14. Levy ME, Wilton L, Phillips G, Glick SN, Kuo I, Brewer RA, et al. Understanding structural barriers to accessing HIV testing and prevention services among black men who have sex with men (BMSM) in the United States. AIDS Behav 2014 May;18(5):972-996 [FREE Full text] [doi: 10.1007/s10461-014-0719-x] [Medline: 24531769]

15. Rowan D, DeSousa M, Randall EM, White C, Holley L. 'We're just targeted as the flock that has HIV': health care experiences of members of the house/ball culture. Soc Work Health Care 2014;53(5):460-477. [doi: 10.1080/00981389.2014.896847] [Medline: 24835090]

16. Dillon FR, Eklund A, Ebersole R, Ertl MM, Martin JL, Verile MG, et al. Heterosexual self-presentation and other individualand community-based correlates of HIV testing among Latino men who have sex with men. Psychol Men Masc 2019 Apr;20(2):238-251 [FREE Full text] [doi: 10.1037/men0000166] [Medline: 31592191]

17. Hatzenbuehler ML, McKetta S, Goldberg N, Sheldon A, Friedman SR, Cooper HL, et al. Trends in state policy support for sexual minorities and HIV-related outcomes among men who have sex with men in the United States, 2008-2014. J Acquir Immune Defic Syndr 2020 Sep 1;85(1):39-45. [doi: 10.1097/QAI.0000000000002395] [Medline: 32398556]

18. Reidpath DD, Chan KY. A method for the quantitative analysis of the layering of HIV-related stigma. AIDS Care 2005 May;17(4):425-432. [doi: 10.1080/09540120412331319769] [Medline: 16036227]

19. Brinkley-Rubinstein L. Understanding the effects of multiple stigmas among formerly incarcerated HIV-positive African American men. AIDS Educ Prev 2015 Apr;27(2):167-179. [doi: 10.1521/aeap.2015.27.2.167] [Medline: 25915701]

20. Bogart LM, Landrine H, Galvan FH, Wagner GJ, Klein DJ. Perceived discrimination and physical health among HIV-positive Black and Latino men who have sex with men. AIDS Behav 2013 May;17(4):1431-1441 [FREE Full text] [doi: 10.1007/s10461-012-0397-5] [Medline: 23297084]

21. Choi K, Paul J, Ayala G, Boylan R, Gregorich SE. Experiences of discrimination and their impact on the mental health among African American, Asian and Pacific Islander, and Latino men who have sex with men. Am J Public Health 2013 May;103(5):868-874 [FREE Full text] [doi: 10.2105/AJPH.2012.301052] [Medline: 23488483]

22. Parsons JT, Millar BM, Moody RL, Starks TJ, Rendina HJ, Grov C. Syndemic conditions and HIV transmission risk behavior among HIV-negative gay and bisexual men in a U.S. national sample. Health Psychol 2017 Jul;36(7):695-703 [FREE Full text] [doi: 10.1037/hea0000509] [Medline: 28541070]

23. Quinn KG. Applying an intersectional framework to understand syndemic conditions among young Black gay, bisexual, and other men who have sex with men. Soc Sci Med 2019 Dec 27:112779. [doi: 10.1016/j.socscimed.2019.112779] [Medline: 31898991]

24. Eke AN, Johnson WD, O'Leary A, Rebchook GM, Huebner DM, Peterson JL, et al. Effect of a community-level hiv prevention intervention on psychosocial determinants of HIV risk behaviors among young black men who have sex with men (YBMSM). AIDS Behav 2019 Sep;23(9):2361-2374. [doi: 10.1007/s10461-019-02499-4] [Medline: 31016504]

25. Frye V, Paige MQ, Gordon S, Matthews D, Musgrave G, Kornegay M, et al. Developing a community-level anti-HIV/AIDS stigma and homophobia intervention in new York city: The project CHHANGE model. Eval Program Plann 2017 Aug;63:45-53. [doi: 10.1016/j.evalprogplan.2017.03.004] [Medline: 28371668]

26. Harper GW, Jadwin-Cakmak L, Cherenak E, Wilson P, Adolescent Medicine Trials Network for HIV/AIDS Interventions. Critical consciousness-based HIV prevention interventions for black gay and bisexual male youth. Am J Sex Educ 2019;14(1):109-133 [FREE Full text] [doi: 10.1080/15546128.2018.1479668] [Medline: 30956625]

27. Nelson LE, Walker JJ, DuBois SN, Giwa S. Your blues ain't like mine: considering integrative antiracism in HIV prevention research with black men who have sex with men in Canada and the United States. Nurs Inq 2014 Dec;21(4):270-282. [doi: 10.1111/nin.12055] [Medline: 24894761]

28. Hosek SG, Lemos D, Hotton AL, Fernandez MI, Telander K, Footer D, et al. An HIV intervention tailored for black young men who have sex with men in the House Ball Community. AIDS Care 2015;27(3):355-362 [FREE Full text] [doi: 10.1080/09540121.2014.963016] [Medline: 25300319]

29. Martinez O, Wu E, Levine EC, Muñoz-Laboy M, Fernandez MI, Bass SB, et al. Integration of social, cultural, and biomedical strategies into an existing couple-based behavioral HIV/STI prevention intervention: voices of Latino male couples. PLoS One 2016;11(3):e0152361 [FREE Full text] [doi: 10.1371/journal.pone.0152361] [Medline: 27028873]

30. Patel VV, Ginsburg Z, Golub SA, Horvath KJ, Rios N, Mayer KH, et al. Empowering with prep (e-prep), a peer-led social media-based intervention to facilitate HIV preexposure prophylaxis adoption among young black and LatinX gay and bisexual men: protocol for a cluster randomized controlled trial. JMIR Res Protoc 2018 Aug 28;7(8):e11375 [FREE Full text] [doi: 10.2196/11375] [Medline: $\underline{30154071]}$ 
31. Bauermeister JA, Muessig KE, Flores DD, LeGrand S, Choi S, Dong W, et al. Stigma Diminishes the Protective Effect of Social Support on Psychological Distress Among Young Black Men Who Have Sex With Men. In: AIDS Education and Prevention. 2018 Presented at: AEP'18; July 23-27, 2018; Amsterdam, the Netherlands URL: http://programme.aids2018.org/ Abstract/Abstract/2695 [doi: 10.1521/aeap.2018.30.5.406]

32. Williams JK, Ramamurthi HC, Manago C, Harawa NT. Learning from successful interventions: a culturally congruent HIV risk-reduction intervention for African American men who have sex with men and women. Am J Public Health 2009 Jun;99(6):1008-1012. [doi: 10.2105/AJPH.2008.140558] [Medline: 19372517]

33. Jones KT, Gray P, Whiteside YO, Wang T, Bost D, Dunbar E, et al. Evaluation of an HIV prevention intervention adapted for Black men who have sex with men. Am J Public Health 2008 Jun;98(6):1043-1050. [doi: 10.2105/AJPH.2007.120337] [Medline: 18445795]

34. Klein CH, Kuhn T, Huxley D, Kennel J, Withers E, Lomonaco CG. Preliminary findings of a technology-delivered sexual health promotion program for black men who have sex with men: quasi-experimental outcome study. JMIR Public Health Surveill 2017 Oct 24;3(4):e78 [FREE Full text] [doi: 10.2196/publichealth.7933] [Medline: 29066422]

35. Stein R, Shapatava E, Williams W, Griffin T, Bell K, Lyons B, et al. Reduced sexual risk behaviors among young men of color who have sex with men: findings from the community-based organization behavioral outcomes of many men, many voices (CBOP-3MV) project. Prev Sci 2015 Nov;16(8):1147-1158. [doi: 10.1007/s11121-015-0565-8] [Medline: 26031542]

36. Ramirez-Valles J, Kuhns LM, Manjarrez D. Tal Como Somos/just as we are: an educational film to reduce stigma toward gay and bisexual men, transgender individuals, and persons living with HIV/AIDS. J Health Commun 2014 Apr;19(4):478-492 [FREE Full text] [doi: 10.1080/10810730.2013.821555] [Medline: 24377496]

37. McKenney J, Sullivan PS, Bowles KE, Oraka E, Sanchez TH, DiNenno E. HIV risk behaviors and utilization of prevention services, urban and rural men who have sex with men in the United States: results from a national online survey. AIDS Behav 2018 Jul;22(7):2127-2136. [doi: 10.1007/s10461-017-1912-5] [Medline: 28986669]

38. Batchelder AW, Klevens M, Fitch C, McKetchnie SM, Mayer KH, O'Cleirigh C. Stigma, discrimination, and substance use among an urban sample men who have sex with men in Massachusetts. AIDS Care 2020 Mar;32(3):370-378. [doi: 10.1080/09540121.2019.1683807] [Medline: 31661969]

39. Fisher CB, Fried AL, Macapagal K, Mustanski B. Patient-provider communication barriers and facilitators to HIV and STI preventive services for adolescent MSM. AIDS Behav 2018 Oct;22(10):3417-3428 [FREE Full text] [doi: 10.1007/s10461-018-2081-x] [Medline: 29546468]

40. Rogers BG, Whiteley L, Haubrick KK, Mena LA, Brown LK. Intervention messaging about pre-exposure prophylaxis use among young, black sexual minority men. AIDS Patient Care STDS 2019 Nov;33(11):473-481. [doi: 10.1089/apc.2019.0139] [Medline: 31682168]

41. Jeffries WL, Townsend ES, Gelaude DJ, Torrone EA, Gasiorowicz M, Bertolli J. HIV stigma experienced by young men who have sex with men (MSM) living with HIV infection. AIDS Educ Prev 2015 Feb;27(1):58-71. [doi:

10.1521/aeap.2015.27.1.58] [Medline: 25646730]

42. Calabrese SK, Mayer KH. Providers should discuss U=U with all patients living with HIV. Lancet HIV 2019 Apr;6(4):e211-e213. [doi: 10.1016/S2352-3018(19)30030-X] [Medline: 30772420]

43. Latkin CA, Davey-Rothwell MA, Knowlton AR, Alexander KA, Williams CT, Boodram B. Social network approaches to recruitment, HIV prevention, medical care, and medication adherence. J Acquir Immune Defic Syndr 2013 Jun 1;63(Suppl 1):S54-S58 [FREE Full text] [doi: 10.1097/QAI.0b013e3182928e2a] [Medline: 23673888]

44. Reed SJ, Miller RL. Thriving and adapting: resilience, sense of community, and syndemics among young black gay and bisexual men. Am J Community Psychol 2016 Mar;57(1-2):129-143. [doi: 10.1002/ajcp.12028] [Medline: 27217317]

45. Amirkhanian YA. Social networks, sexual networks and HIV risk in men who have sex with men. Curr HIV/AIDS Rep 2014 Mar;11(1):81-92 [FREE Full text] [doi: 10.1007/s11904-013-0194-4] [Medline: 24384832]

46. Holloway IW, Tan D, Dunlap SL, Palmer L, Beougher S, Cederbaum JA. Network support, technology use, depression, and ART adherence among HIV-positive MSM of color. AIDS Care 2017 Sep;29(9):1153-1161 [FREE Full text] [doi: 10.1080/09540121.2017.1325435] [Medline: 28488886]

47. Bouris A, Jaffe K, Eavou R, Liao C, Kuhns L, Voisin D, et al. Project ngage: results of a randomized controlled trial of a dyadic network support intervention to retain young black men who have sex with men in HIV care. AIDS Behav 2017 Dec;21(12):3618-3629 [FREE Full text] [doi: 10.1007/s10461-017-1954-8] [Medline: 29079949]

48. DiFulvio GT. Sexual minority youth, social connection and resilience: from personal struggle to collective identity. Soc Sci Med 2011 May;72(10):1611-1617. [doi: 10.1016/j.socscimed.2011.02.045] [Medline: 21497970]

49. Herrick AL, Stall R, Goldhammer H, Egan JE, Mayer KH. Resilience as a research framework and as a cornerstone of prevention research for gay and bisexual men: theory and evidence. AIDS Behav 2014 Jan;18(1):1-9. [doi: 10.1007/s10461-012-0384-x] [Medline: 23321946]

50. Earnshaw VA, Bogart LM, Dovidio JF, Williams DR. Stigma and racial/ethnic HIV disparities: moving toward resilience. Am Psychol 2013;68(4):225-236 [FREE Full text] [doi: 10.1037/a0032705] [Medline: 23688090]

51. Senn TE, Braksmajer A, Coury-Doniger P, Urban MA, Carey MP. Mobile technology use and desired technology-based intervention characteristics among HIV+ Black men who have sex with men. AIDS Care 2017 Apr;29(4):423-427 [FREE Full text] [doi: 10.1080/09540121.2016.1220479] [Medline: 27535069] 
52. Levy ME, Watson CC, Wilton L, Criss V, Kuo I, Glick SN, et al. Acceptability of a mobile smartphone application intervention to improve access to HIV prevention and care services for black men who have sex with men in the district of Columbia. Digit Cult Educ 2015;7(2):169-191 [FREE Full text] [Medline: 26594251]

53. Holloway IW, Winder TJ, Lea CH, Tan D, Boyd D, Novak D. Technology use and preferences for mobile phone-based HIV prevention and treatment among black young men who have sex with men: exploratory research. JMIR Mhealth Uhealth 2017 Apr 13;5(4):e46 [FREE Full text] [doi: 10.2196/mhealth.6436] [Medline: 28408360]

54. Mulawa MI, LeGrand S, Hightow-Weidman LB. Ehealth to enhance treatment adherence among youth living with HIV. Curr HIV/AIDS Rep 2018 Aug;15(4):336-349 [FREE Full text] [doi: 10.1007/s11904-018-0407-y] [Medline: 29959649]

55. Flickinger TE, DeBolt C, Xie A, Kosmacki A, Grabowski M, Waldman AL, et al. Addressing stigma through a virtual community for people living with HIV: a mixed methods study of the positivelinks mobile health intervention. AIDS Behav 2018 Oct;22(10):3395-3406 [FREE Full text] [doi: 10.1007/s10461-018-2174-6] [Medline: 29882048]

56. Hightow-Weidman LB, Muessig KE, Pike EC, LeGrand S, Baltierra N, Rucker AJ, et al. Healthmpowerment.org: building community through a mobile-optimized, online health promotion intervention. Health Educ Behav 2015 Aug;42(4):493-499 [FREE Full text] [doi: 10.1177/1090198114562043] [Medline: 25588932]

57. Mobile Fact Sheet. Pew Research Center. 2019. URL: https://www.pewresearch.org/internet/fact-sheet/mobile/ [accessed 2020-09-03]

58. Hightow-Weidman LB, LeGrand S, Muessig KE, Simmons RA, Soni K, Choi SK, et al. A randomized trial of an online risk reduction intervention for young black MSM. AIDS Behav 2019 May;23(5):1166-1177 [FREE Full text] [doi: 10.1007/s10461-018-2289-9] [Medline: 30269231]

59. Refugio ON, Kimble MM, Silva CL, Lykens JE, Bannister C, Klausner JD. Brief report: preptech: a telehealth-based initiation program for HIV pre-exposure prophylaxis in young men of color who have sex with men. A pilot study of feasibility. J Acquir Immune Defic Syndr 2019 Jan 1;80(1):40-45 [FREE Full text] [doi: 10.1097/QAI.0000000000001873] [Medline: 30272632]

60. Schnall R, Kuhns LM, Hidalgo MA, Powell D, Thai J, Hirshfield S, et al. Adaptation of a group-based HIV risk reduction intervention to a mobile app for young sexual minority men. AIDS Educ Prev 2018 Dec;30(6):449-462 [FREE Full text] [doi: 10.1521/aeap.2018.30.6.449] [Medline: 30966769]

61. Solorio R, Norton-Shelpuk P, Forehand M, Montaño D, Stern J, Aguirre J, et al. Tu amigo pepe: evaluation of a multi-media marketing campaign that targets young Latino immigrant MSM with HIV testing messages. AIDS Behav 2016 Sep;20(9):1973-1988. [doi: 10.1007/s10461-015-1277-6] [Medline: 26850101]

62. Stephenson R, Todd K, Kahle E, Sullivan SP, Miller-Perusse M, Sharma A, et al. Project moxie: results of a feasibility study of a telehealth intervention to increase HIV testing among binary and nonbinary transgender youth. AIDS Behav 2020 May;24(5):1517-1530. [doi: 10.1007/s10461-019-02741-z] [Medline: $\underline{\text { 31760536] }}$

63. Dworkin M, Chakraborty A, Lee S, Monahan C, Hightow-Weidman L, Garofalo R, et al. A realistic talking human embodied agent mobile phone intervention to promote HIV medication adherence and retention in care in young HIV-positive African American men who have sex with men: qualitative study. JMIR Mhealth Uhealth 2018 Jul 31;6(7):e10211 [FREE Full text] [doi: 10.2196/10211] [Medline: 30064971]

64. Li AT, Fung KP, Maticka-Tyndale E, Wong JP. Effects Of HIV stigma reduction interventions in diasporic communities: insights from the CHAMP study. AIDS Care 2018 Jun;30(6):739-745. [doi: 10.1080/09540121.2017.1391982] [Medline: 29063782]

65. Barry MC, Threats M, Blackburn NA, LeGrand S, Dong W, Pulley DV, et al. 'Stay strong! keep ya head up! move on! it gets better!!!!': resilience processes in the healthMpowerment online intervention of young black gay, bisexual and other men who have sex with men. AIDS Care 2018 Aug;30(sup5):S27-S38 [FREE Full text] [doi: 10.1080/09540121.2018.1510106] [Medline: 30632775]

66. Bauermeister JA, Muessig KE, Flores DD, LeGrand S, Choi S, Dong W, et al. Stigma diminishes the protective effect of social support on psychological distress among young black men who have sex with men. AIDS Educ Prev 2018 Oct;30(5):406-418 [FREE Full text] [doi: 10.1521/aeap.2018.30.5.406] [Medline: 30332312]

67. Bauermeister JA, Muessig KE, LeGrand S, Flores DD, Choi SK, Dong W, et al. HIV and sexuality stigma reduction through engagement in online forums: results from the healthmpowerment intervention. AIDS Behav 2019 Mar;23(3):742-752 [FREE Full text] [doi: 10.1007/s10461-018-2256-5] [Medline: 30121727]

68. Bauermeister JA, Golinkoff JM, Muessig KE, Horvath KJ, Hightow-Weidman LB. Addressing engagement in technology-based behavioural HIV interventions through paradata metrics. Curr Opin HIV AIDS 2017 Sep;12(5):442-446 [FREE Full text] [doi: 10.1097/COH.0000000000000396] [Medline: 28617711]

69. Baltierra NB, Muessig KE, Pike EC, LeGrand S, Bull SS, Hightow-Weidman LB. More than just tracking time: complex measures of user engagement with an internet-based health promotion intervention. J Biomed Inform 2016 Feb;59:299-307 [FREE Full text] [doi: 10.1016/j.jbi.2015.12.015] [Medline: 26732997]

70. Bonett S, Connochie D, Golinkoff JM, Horvath KJ, Bauermeister JA. Paradata analysis of an ehealth HIV testing intervention for young men who have sex with men. AIDS Educ Prev 2018 Oct;30(5):434-447 [FREE Full text] [doi:

10.1521/aeap.2018.30.5.434] [Medline: 30332307] 
71. Hightow-Weidman LB, Bauermeister JA. Engagement in mHealth behavioral interventions for HIV prevention and care:

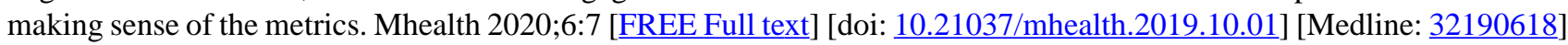

72. Jemmott JB, Jemmott LS, O'Leary A, Icard LD, Rutledge SE, Stevens R, et al. On the efficacy and mediation of a one-on-one hiv risk-reduction intervention for African American men who have sex with men: a randomized controlled trial. AIDS Behav 2015 Jul;19(7):1247-1262 [FREE Full text] [doi: 10.1007/s10461-014-0961-2] [Medline: 25449552]

73. Hermanstyne KA, Green HD, Cook R, Tieu H, Dyer TV, Hucks-Ortiz C, et al. Social network support and decreased risk of seroconversion in black MSM: results of the brothers (HPTN 061) study. J Acquir Immune Defic Syndr 2018 Jun 1;78(2):163-168 [FREE Full text] [doi: 10.1097/QAI.0000000000001645] [Medline: 29424789]

74. Hergenrather KC, Emmanuel D, Durant S, Rhodes SD. Enhancing HIV prevention among young men who have sex with men: a systematic review of HIV behavioral interventions for young gay and bisexual men. AIDS Educ Prev 2016 Jun;28(3):252-271. [doi: 10.1521/aeap.2016.28.3.252] [Medline: 27244193]

75. Abuelezam NN, Reshef YA, Novak D, Grad YH, Seage Iii GR, Mayer K, et al. Interaction patterns of men who have sex with men on a geosocial networking mobile app in seven united states metropolitan areas: observational study. J Med Internet Res 2019 Sep 12;21(9):e13766 [FREE Full text] [doi: 10.2196/13766] [Medline: 31516124]

76. Winder TJA, Lea CH. 'Blocking' and 'filtering': a commentary on mobile technology, racism, and the sexual networks of young black MSM (YBMSM). J Racial Ethn Health Disparities 2019 Apr;6(2):231-236. [doi: 10.1007/s40615-018-0493-y] [Medline: 29713916]

77. Friedman MR, Coulter RW, Silvestre AJ, Stall R, Teplin L, Shoptaw S, et al. Someone to count on: social support as an effect modifier of viral load suppression in a prospective cohort study. AIDS Care 2017 Apr;29(4):469-480 [FREE Full text] [doi: $10.1080 / 09540121.2016 .1211614$ ] [Medline: 27456040$]$

78. Kobus K, Henry DB. Interplay of network position and peer substance use in early adolescent cigarette, alcohol, and marijuana use. J Early Adolesc 2009 Mar 6;30(2):225-245. [doi: 10.1177/0272431609333300]

79. Fujimoto K, Valente TW. Decomposing the components of friendship and friends' influence on adolescent drinking and smoking. J Adolesc Health 2012 Aug;51(2):136-143 [FREE Full text] [doi: 10.1016/j.jadohealth.2011.11.013] [Medline: 22824443]

80. Young SD, Holloway I, Jaganath D, Rice E, Westmoreland D, Coates T. Project HOPE: online social network changes in an HIV prevention randomized controlled trial for African American and Latino men who have sex with men. Am J Public Health 2014 Sep;104(9):1707-1712. [doi: 10.2105/AJPH.2014.301992] [Medline: 25033137]

81. Hamilton DT, Handcock MS, Morris M. Degree distributions in sexual networks: a framework for evaluating evidence. Sex Transm Dis 2008 Jan;35(1):30-40 [FREE Full text] [doi: 10.1097/olq.0b013e3181453a84] [Medline: 18217224]

82. De Rubeis E, Wylie JL, Cameron DW, Nair RC, Jolly AM. Combining social network analysis and cluster analysis to identify sexual network types. Int J STD AIDS 2007 Nov;18(11):754-759. [doi: 10.1258/095646207782212234] [Medline: $\underline{18005509]}$

83. Valente TW, Fosados R. Diffusion of innovations and network segmentation: the part played by people in promoting health. Sex Transm Dis 2006 Jul;33(7 Suppl):S23-S31. [doi: 10.1097/01.olq.0000221018.32533.6d] [Medline: 16794552]

84. Smith AM, Grierson J, Wain D, Pitts M, Pattison P. Associations between the sexual behaviour of men who have sex with men and the structure and composition of their social networks. Sex Transm Infect 2004 Dec;80(6):455-458 [FREE Full text] [doi: 10.1136/sti.2004.010355] [Medline: 15572613 ]

85. Kohler H, Behrman JR, Watkins SC. Social networks and HIV/AIDs risk perceptions. Demography 2007 Feb;44(1):1-33. [doi: 10.1353/dem.2007.0006] [Medline: 17461334]

86. McCumber M, Cain D, LeGrand S, Mayer KH, Murphy DA, Psioda MA, et al. Adolescent medicine trials network for HIV/AIDS interventions data harmonization: rationale and development of guidelines. JMIR Res Protoc 2018 Dec 21;7(12):e11207 [FREE Full text] [doi: 10.2196/11207] [Medline: 30578242]

87. Hightow-Weidman LB, Fowler B, Kibe J, McCoy R, Pike E, Calabria M, et al. HealthMpowerment.org: development of a theory-based HIV/STI website for young black MSM. AIDS Educ Prev 2011 Feb;23(1):1-12 [FRE Full text] [doi: 10.1521/aeap.2011.23.1.1] [Medline: 21341956]

88. Turan B, Hatcher AM, Weiser SD, Johnson MO, Rice WS, Turan JM. Framing mechanisms linking HIV-related stigma, adherence to treatment, and health outcomes. Am J Public Health 2017 Jun;107(6):863-869. [doi: 10.2105/AJPH.2017.303744] [Medline: 28426316]

89. Hatzenbuehler ML. Structural stigma: research evidence and implications for psychological science. Am Psychol 2016 Nov;71(8):742-751 [FREE Full text] [doi: 10.1037/amp0000068] [Medline: 27977256]

90. Viruell-Fuentes EA. Beyond acculturation: immigration, discrimination, and health research among Mexicans in the United States. Soc Sci Med 2007 Oct;65(7):1524-1535. [doi: 10.1016/j.socscimed.2007.05.010] [Medline: 17602812]

91. Viruell-Fuentes EA, Miranda PY, Abdulrahim S. More than culture: structural racism, intersectionality theory, and immigrant health. Soc Sci Med 2012 Dec;75(12):2099-2106. [doi: 10.1016/j.socscimed.2011.12.037] [Medline: 22386617]

92. Muessig K, Barry M, Dong W, Pulley D, Blackburn N, Sallabank G, et al. How Do We as Young Black Gay Men Stand Strong?: the Healthmpowerment Online Intervention as a Space to Engage With Stigma Related to HIV, Sexuality, and Race. In: 9th International AIDS Society Conference on HIV Science. 2018 Presented at: IAS'17; July 23-26, 2017; Paris, France. [doi: 10.1080/09540121.2018.1510106] 
93. Arnold EA, Rebchook GM, Kegeles SM. 'Triply cursed': racism, homophobia and HIV-related stigma are barriers to regular HIV testing, treatment adherence and disclosure among young Black gay men. Cult Health Sex 2014 Jun;16(6):710-722 [FREE Full text] [doi: 10.1080/13691058.2014.905706] [Medline: 24784224]

94. Herek GM, Mitnick L, Burris S, Chesney M, Devine P, Fullilove MT, et al. Workshop report: AIDS and stigma: a conceptual framework and research agenda. AIDS Public Policy J 1998;13(1):36-47. [Medline: 10915271]

95. Kalichman SC, Simbayi LC, Cloete A, Mthembu PP, Mkhonta RN, Ginindza T. Measuring AIDS stigmas in people living with HIV/AIDS: the internalized AIDS-related stigma scale. AIDS Care 2009 Jan;21(1):87-93. [doi: 10.1080/09540120802032627] [Medline: 19085224]

96. Earnshaw VA, Smith LR, Chaudoir SR, Amico KR, Copenhaver MM. HIV stigma mechanisms and well-being among PLWH: a test of the HIV stigma framework. AIDS Behav 2013 Jun;17(5):1785-1795 [FREE Full text] [doi: 10.1007/s10461-013-0437-9] [Medline: 23456594]

97. Smith R, Rossetto K, Peterson BL. A meta-analysis of disclosure of one's HIV-positive status, stigma and social support. AIDS Care 2008 Nov;20(10):1266-1275. [doi: 10.1080/09540120801926977] [Medline: 18608080 ]

98. Hatzenbuehler ML, O'Cleirigh C, Mayer KH, Mimiaga MJ, Safren SA. Prospective associations between HIV-related stigma, transmission risk behaviors, and adverse mental health outcomes in men who have sex with men. Ann Behav Med 2011 Oct;42(2):227-234 [FREE Full text] [doi: 10.1007/s12160-011-9275-z] [Medline: 21533623]

99. Bauermeister JA, Zimmerman MA, Johns MM, Glowacki P, Stoddard S, Volz E. Innovative recruitment using online networks: lessons learned from an online study of alcohol and other drug use utilizing a web-based, respondent-driven sampling (webRDS) strategy. J Stud Alcohol Drugs 2012 Sep;73(5):834-838 [FREE Full text] [doi: 10.15288/jsad.2012.73.834] [Medline: 22846248]

100. HemaSpot-HF Blood Collection Device. Spotonsciences. 2017. URL: https://www.spotonsciences.com/ [accessed 2020-09-03]

101. Hirshfield S, Teran RA, Downing MJ, Chiasson MA, Tieu H, Dize L, et al. Quantification of HIV-1 RNA among men who have sex with men using an at-home self-collected dried blood spot specimen: feasibility study. JMIR Public Health Surveill 2018 Nov 1;4(4):e10847 [FREE Full text] [doi: 10.2196/10847] [Medline: 30389648]

102. Teran RA, Sobieszczyk ME, Chiasson MA, Uhlemann A, Weidler J, Shah JG, et al. Longitudinal viral load monitoring using home-collected dried blood spot specimens of MSM living with HIV: results from a feasibility pilot study. AIDS Behav 2020 Sep 9:- epub ahead of print. [doi: 10.1007/s10461-020-03030-w] [Medline: $\underline{32909080]}$

103. OraQuick: In-home HIV Test. OraSure Technologies Inc. 2016. URL: http://www.oraquick.com/Home [accessed 2020-09-03]

104. Teitcher JE, Bockting WO, Bauermeister JA, Hoefer CJ, Miner MH, Klitzman RL. Detecting, preventing, and responding to 'fraudsters' in internet research: ethics and tradeoffs. J Law Med Ethics 2015;43(1):116-133 [FREE Full text] [doi: 10.1111/jlme.12200] [Medline: 25846043]

105. Bauermeister J, Sullivan PS, Gravens L, Wolfe J, Countryman K, Smith-Bankhead N, et al. Reducing HIV vulnerability through a multilevel life skills intervention for adolescent men (the iReach project): protocol for a randomized controlled trial. JMIR Res Protoc 2018 Jul 10;7(7):e10174 [FREE Full text] [doi: 10.2196/10174] [Medline: 29991470]

106. LeGrand S, Muessig KE, Platt A, Soni K, Egger JR, Nwoko N, et al. Epic allies, a gamified mobile phone app to improve engagement in care, antiretroviral uptake, and adherence among young men who have sex with men and young transgender women who have sex with men: protocol for a randomized controlled trial. JMIR Res Protoc 2018 Apr 5;7(4):e94 [FREE Full text] [doi: 10.2196/resprot.8811] [Medline: 29622527]

107. Ford MA, Spicer CM, editors. Monitoring HIV Care in the United States: Indicators and Data Systems. Washington, DC: National Academies Press; Mar 15, 2012.

108. DiNenno EA, Prejean J, Irwin K, Delaney KP, Bowles K, Martin T, et al. Recommendations for HIV screening of gay, bisexual, and other men who have sex with men - United States, 2017. MMWR Morb Mortal Wkly Rep 2017 Aug 11;66(31):830-832 [FREE Full text] [doi: 10.15585/mmwr.mm6631a3] [Medline: 28796758]

109. Norman CD, Skinner HA. eHEALS: the eHealth literacy scale. J Med Internet Res 2006 Nov 14;8(4):e27 [FREE Full text] [doi: 10.2196/jmir.8.4.e27] [Medline: 17213046 ]

110. Mugavero MJ, Davila JA, Nevin CR, Giordano TP. From access to engagement: measuring retention in outpatient HIV clinical care. AIDS Patient Care STDS 2010 Oct;24(10):607-613 [FREE Full text] [doi: 10.1089/apc.2010.0086] [Medline: 20858055]

111. Wilson IB, Fowler FJ, Cosenza CA, Michaud J, Bentkover J, Rana A, et al. Cognitive and field testing of a new set of medication adherence self-report items for HIV care. AIDS Behav 2014 Dec;18(12):2349-2358 [FREE Full text] [doi: 10.1007/s10461-013-0610-1] [Medline: 24077970]

112. Bauermeister JA, Meanley S, Pingel E, Soler JH, Harper GW. PrEP awareness and perceived barriers among single young men who have sex with men. Curr HIV Res 2013 Oct;11(7):520-527 [FREE Full text] [doi: 10.2174/1570162x12666140129100411] [Medline: 24476355]

113. Herek G, Berril K, editors. Hate Crimes: Confronting Violence Against Lesbians and Gay Men. Newbury Park, USA: Sage Publications; 1992.

114. Berger BE, Ferrans CE, Lashley FR. Measuring stigma in people with HIV: psychometric assessment of the HIV stigma scale. Res Nurs Health 2001 Dec;24(6):518-529. [doi: 10.1002/nur.10011] [Medline: 11746080] 
115. Testa R, Habarth J, Peta J, Balsam K, Bockting W. Development of the gender minority stress and resilience measure. Psychol Sex Orientation Gender Diver 2015;2(1):65-77 [FREE Full text] [doi: 10.1037/t39597-000]

116. Krieger N, Smith K, Naishadham D, Hartman C, Barbeau EM. Experiences of discrimination: validity and reliability of a self-report measure for population health research on racism and health. Soc Sci Med 2005 Oct;61(7):1576-1596. [doi: 10.1016/j.socscimed.2005.03.006] [Medline: 16005789]

117. Williams DR, Yu Y, Jackson JS, Anderson NB. Racial differences in physical and mental health: socio-economic status, stress and discrimination. J Health Psychol 1997 Jul;2(3):335-351. [doi: 10.1177/135910539700200305] [Medline: 22013026]

118. Herek G, Gillis J, Cogan J. Internalized stigma among sexual minority adults: insights from a social psychological perspective. J Counsel Psychol 2009 Jan;56(1):32-43 [FREE Full text] [doi: 10.1037/a0014672]

119. Turan B, Budhwani H, Fazeli PL, Browning WR, Raper JL, Mugavero MJ, et al. How does stigma affect people living with hiv? The mediating roles of internalized and anticipated hiv stigma in the effects of perceived community stigma on health and psychosocial outcomes. AIDS Behav 2017 Jan;21(1):283-291 [FREE Full text] [doi: 10.1007/s10461-016-1451-5] [Medline: 27272742]

120. Firmin RL, Lysaker PH, McGrew JH, Minor KS, Luther L, Salyers MP. The stigma resistance scale: a multi-sample validation of a new instrument to assess mental illness stigma resistance. Psychiatry Res 2017 Dec;258:37-43. [doi: 10.1016/j.psychres.2017.09.063] [Medline: 28985551]

121. Ader DN. Developing the patient-reported outcomes measurement information system (PROMIS). Med Care 2007;45(Suppl 1):S1-S2 [FREE Full text] [doi: 10.1097/01.mlr.0000260537.45076.74]

122. Kroenke K, Strine TW, Spitzer RL, Williams JB, Berry JT, Mokdad AH. The PHQ-8 as a measure of current depression in the general population. J Affect Disord 2009 Apr;114(1-3):163-173. [doi: 10.1016/j.jad.2008.06.026] [Medline: 18752852]

123. Spitzer RL, Kroenke K, Williams JB, Löwe B. A brief measure for assessing generalized anxiety disorder: the GAD-7. Arch Intern Med 2006 May 22;166(10):1092-1097. [doi: 10.1001/archinte.166.10.1092] [Medline: 16717171]

124. Johnson MO, Neilands TB, Dilworth SE, Morin SF, Remien RH, Chesney MA. The role of self-efficacy in HIV treatment adherence: validation of the HIV treatment adherence self-efficacy scale (HIV-ASES). J Behav Med 2007 Oct;30(5):359-370 [FREE Full text] [doi: 10.1007/s10865-007-9118-3] [Medline: 17588200]

125. Rosenberg M. Society and the Adolescent Self-Image. Princeton, NJ: Princeton University Press; 1965.

126. WHO ASSIST Working Group. The alcohol, smoking and substance involvement screening test (ASSIST): development, reliability and feasibility. Addiction 2002 Sep;97(9):1183-1194. [doi: 10.1046/j.1360-0443.2002.00185.x] [Medline: 12199834]

127. Bauermeister JA. Sexual partner typologies among single young men who have sex with men. AIDS Behav 2015 Jun;19(6):1116-1128 [FREE Full text] [doi: 10.1007/s10461-014-0932-7] [Medline: 25358726]

128. Teplin LA, Elkington KS, McClelland GM, Abram KM, Mericle AA, Washburn JJ. Major mental disorders, substance use disorders, comorbidity, and HIV-AIDS risk behaviors in juvenile detainees. Psychiatr Serv 2005 Jul;56(7):823-828 [FREE Full text] [doi: 10.1176/appi.ps.56.7.823] [Medline: 16020814]

129. Meadowbrooke CC, Veinot TC, Loveluck J, Hickok A, Bauermeister JA. Information behavior and HIV testing intentions among young men at risk for HIV/AIDS. J Assoc Inf Sci Technol 2014 Mar;65(3):609-620 [FREE Full text] [doi: 10.1002/asi.23001] [Medline: 25346934]

130. Veinot TC, Meadowbrooke CC, Loveluck J, Hickok A, Bauermeister JA. How 'community' matters for how people interact with information: mixed methods study of young men who have sex with other men. J Med Internet Res 2013 Feb 21;15(2):e33 [FREE Full text] [doi: 10.2196/jmir.2370] [Medline: 23428825]

131. Youm Y, Laumann EO. Social network effects on the transmission of sexually transmitted diseases. Sex Transm Dis 2002 Nov;29(11):689-697. [doi: 10.1097/00007435-200211000-00012] [Medline: 12438906]

132. Arriola E. Faeries, marimachas, queens, and lezzies: the construction of homosexuality before the 1969 stonewall riots. Columbia J Gender Law 1995;5(1):33 [FREE Full text] [doi: 10.7916/cjgl.v5i1.2378]

133. Hutchinson D. 'Gay rights' for 'gay whites'?: race, sexual identity, and equal protection discourse. 85 Cornell Law Rev 2000;1358:- [FREE Full text] [doi: 10.7208/chicago/9780226451039.003.0002]

134. Carbado DW. Black rights, gay rights, civil rights. In: Fineman MA, Jackson JE, Romero AP, editors. Feminist and Queer Legal Theory: Intimate Encounters, Uncomfortable Conversations. Ashgate: Farnham; 2009:223-243.

135. Miles MB, Huberman AM. Qualitative Data Analysis: An Expanded Sourcebook. Second Edition. Thousand Oaks, CA: Sage Publications; 1994.

\section{Abbreviations}

ART: antiretroviral therapy

CAI: condomless anal intercourse

HMP: HealthMpowerment

IRB: institutional review board

mHealth: mobile health

mPI: multiple principal investigator 
MSM: men who have sex with men

NIMH: National Institute of Mental Health

OR: odds ratio

PrEP: pre-exposure prophylaxis

RCT: randomized controlled trial

TW: transgender women

$\mathbf{U}=\mathbf{U}$ : undetectable equals untransmittable

VS: viral suppression

YAB: youth advisory board

YBLMT: young Black and Latinx men who have sex with men and transgender women who have sex with men

Edited by G Eysenbach; submitted 04.09.20; peer-reviewed by C Lelutiu-Weinberger, C Klein; comments to author 21.10.20; revised version received 03.11.20; accepted 03.11.20; published 16.12.20

Please cite as:

Muessig KE, Golinkoff JM, Hightow-Weidman LB, Rochelle AE, Mulawa MI, Hirshfield S, Rosengren AL, Aryal S, Buckner N, Wilson MS, Watson DL, Houang S, Bauermeister JA

Increasing HIV Testing and Viral Suppression via Stigma Reduction in a Social Networking Mobile Health Intervention Among Black and Latinx Young Men and Transgender Women Who Have Sex With Men (HealthMpowerment): Protocol for a Randomized Controlled

Trial

JMIR Res Protoc 2020;9(12):e24043

URL: https://www.researchprotocols.org/2020/12/e24043

doi: $10.2196 / 24043$

PMID: $\underline{3325838}$

CKathryn Elizabeth Muessig, Jesse M Golinkoff, Lisa B Hightow-Weidman, Aimee E Rochelle, Marta I Mulawa, Sabina Hirshfield, A Lina Rosengren, Subhash Aryal, Nickie Buckner, M Skye Wilson, Dovie L Watson, Steven Houang, José Arturo Bauermeister. Originally published in JMIR Research Protocols (http://www.researchprotocols.org), 16.12.2020. This is an open-access article distributed under the terms of the Creative Commons Attribution License (https://creativecommons.org/licenses/by/4.0/), which permits unrestricted use, distribution, and reproduction in any medium, provided the original work, first published in JMIR Research Protocols, is properly cited. The complete bibliographic information, a link to the original publication on http://www.researchprotocols.org, as well as this copyright and license information must be included. 